\title{
Neuroinflammatory and behavioral susceptibility profile of mice exposed to social stress towards cocaine effects
}

\author{
Raúl Ballestín $^{\mathrm{a}, 1}$, Laia Alegre-Zurano ${ }^{\mathrm{b}, 1}$, Carmen Ferrer-Pérez ${ }^{\mathrm{a}}$, Lídia Cantacorps ${ }^{\mathrm{b}}$, José Miñarro ${ }^{\mathrm{a}}$, \\ Olga Valverde ${ }^{\mathrm{b}, \mathrm{c}}$, Marta Rodríguez-Arias ${ }^{\mathrm{a},}$ \\ ${ }^{a}$ Unidad de Investigación Psicobiología de las Drogodependencias, Departamento de Psicobiología, Facultad de Psicología, Universitat de València, Valencia, Spain \\ ${ }^{\mathrm{b}}$ Neurobiology of Behavior Research Group (GReNeC-NeuroBio), Department of Health and Experimental Sciences, University Pompeu Fabra, Spain \\ ' IMIM (Hospital del Mar Medical Research Institute), Barcelona, Spain
}

\section{A R T I C L E I N F O}

\section{Keywords:}

Neuroinflammation

Social defeat

Cocaine

Susceptibility

Resilience

Cytokine

Chemokine

\begin{abstract}
A B S T R A C T
Using the social defeat (SD) model, numerous studies have shown that stressed mice display an enhanced response to the motivational effects of cocaine in the self-administration (SA) and conditioned-place preference (CPP) paradigms. However, not all subjects exposed to stress express its harmful effects. Some are particularly susceptible to the deleterious effects of repeated SD, while resilient mice successfully cope with stressful experiences and display adjusted psychological functioning after stress. Vulnerability to develop stress-related disorders, such as depression, has been linked to coping strategies and more recently to individual differences in the immune system. However, no studies have evaluated if coping strategies and immune system reactivity to social stress experiences can also predict susceptibility to stress-induced enhancement of the cocaine response. We evaluated cocaine response in socially defeated mice in the CPP and SA paradigms. To evaluate neuroimmune reactivity to stress the pro-inflammatory cytokine IL- 6 and the chemokine CX3CL1 were measured in the striatum and hippocampus. Behavioral phenotype during and after SD episodes was also evaluated. Our results showed that susceptible mice to the depressive-like behaviors effects of stress showed increased conditioned rewarding effects of cocaine in the CPP. In addition, susceptible mice displayed passive-reactive coping behavior during social stress episodes and more pronounced changes in neuroinflammatory markers after the last SD episode, which lasted for one month. Although the complex mechanisms underlying susceptibility or resilience to social stress are still unclear, our results point to multiple adaptive stress responses expressed at different phenotypic levels.
\end{abstract}

\section{Introduction}

In today's society, psychosocial stress is an inescapable part of our daily routine. We face demanding situations on a daily basis, such as conflicts between work and family life, arguments with children and partner, or constant deadlines that can have a negative impact on our global welfare (Almeida, 2005). Numerous studies link this chronic exposure to stress to some epidemic diseases, such as obesity, depression (Ouakinin et al., 2018) and drug addiction (Koob and Schulkin, 2019; Ruisoto and Contador, 2019). In fact, social stress is considered to be a risk factor that influences all stages of the addictive process, from initiation, maintenance and escalation of intake to relapse into drug taking (Koob, 2008; Koob and Schulkin, 2019).

Animal models are useful to characterize the impact of stress on drug response and to understand the underlying neurobiological mechanisms (Lynch et al., 2010). The most common animal model for studying social stress in rodents is the resident-intruder paradigm, or social defeat (SD) model, which encourages the expression of natural offensive and defensive behaviors. In this model, an experimental animal (intruder) is confronted with an aggressive opponent (resident) in its home cage in a repeated, intermittent manner (Miczek et al., 2008). Exposure to different procedures of SD has been shown to enhance a

\footnotetext{
Abbreviations: CPP, conditioned place preference; CRF, corticotropin-releasing factor; CX3CL1, C-X ${ }_{3}$-C motif ligand 1 (fractalkine); HPA, hypothalamic-pituitary-

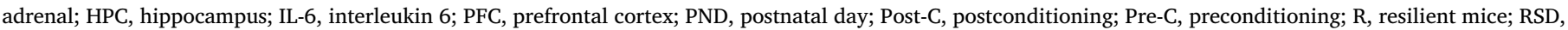
repeated social defeat; S, susceptible mice; SA, self-administration; SD, social defeat; STR, striatum; SWR, social withdrawal ratio

* Corresponding author at: Departamento de Psicobiología, Facultad de Psicología, Universitat de València, Avda. Blasco Ibáñez, 21, 46010 Valencia, Spain.

E-mail address: marta.rodriguez@uv.es (M. Rodríguez-Arias).

${ }^{1}$ Both authors equally contributed to the paper.
} 
rodent's response to the unconditioned and conditioned rewarding effects of psychostimulant drugs. For instance, stressed mice display an enhanced response to rewarding and reinstating effects of cocaine in the self-administration (SA) and conditioned-place preference (CPP) paradigms (Ferrer-Pérez et al., 2018; Han et al., 2017; MontagudRomero et al., 2018; Neisewander et al., 2012; Reguilón et al., 2017; Shimamoto, 2018). Similarly, stress experiences increase sensitivity to cocaine-induced hyperactivity and dopaminergic cross-sensitization (Covington 3rd et al., 2008).

However, not all subjects exposed to stress will display unhealthy behaviors and develop addiction (Krishnan et al., 2007). There are subjects particularly susceptible to the effects of repeated social defeat that exhibit social avoidance, decreased sucrose preference, decreased circadian amplitude of body temperature, social hyperthermia, and weight loss (Krishnan et al., 2007). In contrast to susceptible mice, their resilient counterparts successfully cope with stressful experiences and display an adjusted psychological functioning after stress (Brockhurst et al., 2015; Charney, 2004; Dantzer et al., 2018). It is important to note that resilient mice also show stress-related symptoms, like susceptible animals, such as anxiety-like behavior, and higher corticosterone levels (Krishnan et al., 2007). With regard to this, a considerable body of clinical and pre-clinical research has addressed a series of factors involved in susceptibility or resilience to the deleterious consequences of stress (Cathomas et al., 2019; Dutcher and Creswell, 2018). The studies in question suggest that a correct reaction of the body to acute stress challenges is crucial for an adaptive response to the environment and to avoid stress-related deficits (Cathomas et al., 2019).

Clinical and preclinical studies have highlighted that passive rather than active coping strategies are linked to stress-induced maladaptive behaviors (Hawley et al., 2010; Russo et al., 2012; Wood and Bhatnagar, 2015). For instance, in the context of SD, two different phenotypes of behaviors can be observed among rodents submitted to episodes of stress (Wood et al., 2010). Some animals exhibit passivereactive coping strategies, such as submissive and immobile behavior. On the other hand, others display an active coping phenotype with higher latency to display the defeat posture, fight-back or active escape rather than immobility (Koolhaas et al., 2007; Wood et al., 2010). These two behavioral patterns during stress episodes produce different consequences, with animals that display passive coping proving more susceptible to physiological effects and psychopathology (Hawley et al., 2010; Russo et al., 2012; Wood and Bhatnagar, 2015).

As the stress response is multidimensional and multisystem, it encompasses not only the behavioral response during stress, but also its physiological processes (Murrough and Russo, 2019). In fact, vulnerability to stress-related disorders such as depression has recently been linked to individual differences in the immune system (Hodes et al., 2014; Wood et al., 2015). Pre-clinical research into depression has revealed that differences in the reactivity of the inflammatory response after stress can predict if a mouse will display depressive-like consequences of stress, such as social avoidance or, on the other hand, a resilient phenotype. In this regard, Hodes et al. (2014) reported a less reactive immune system with lower levels of pro-inflammatory cytokines in resilient mice after acute stress, while susceptible mice displayed an exaggerated pro-inflammatory response. Some authors have also evaluated the link between the stress coping phenotype and its immune consequences, using it to predict resilience or susceptibility. These studies suggest that animals displaying active coping strategies undergo decreased inflammatory processes, whereas animals displaying passive-reactive coping strategies tend to display pro-inflammatory processes (Wood et al., 2015). Moreover, the negative consequences of passive coping during stress can be buffered by reducing stress-induced inflammation (Dantzer et al., 2018).

Considering the devastating consequences of addiction, it is necessary to study which factors can predict an increased susceptibility to develop drug-related disorders after stress. There is a close association between the brain systems that regulate stress and those responsible for responses to drugs of abuse, suggesting that social stressors modify the brain's reward system function (Rodríguez-Arias et al., 2013a). Although there is vast literature evaluating the factors that predict susceptibility and resilience to depression-like stress consequences, no study to date has evaluated if coping strategies and immune system reactivity to social stress experiences can also predict susceptibility to a stress-induced enhancement of the cocaine response. In the present study, we have evaluated if the phenotype in resilient or susceptible subjects after SD episodes based on the development of social avoidance can also predict susceptibility to modulate cocaine response by using the CPP and SA paradigms. Additionally, we have characterized the reactivity of these mice to stress by measuring IL-6, a pro-inflammatory cytokine, and CX3CL1, a poorly characterized chemokine, both of which are reported to be altered by social stress experiences and to mediate stress impact on cocaine response (Ferrer-Pérez et al., 2018; Hodes et al., 2014; Montagud-Romero et al., 2020). The study of which factors determine stress susceptibility, and which promote resilience to the impact of stress on cocaine response will certainly lead to new and improved therapeutic opportunities.

\section{Methodology}

\subsection{Animals}

A total number of 142 adult male C57BL/6 mice (Charles River, France) were used in this study. Experimental mice were housed in groups of five in plastic cages $(27 \times 27 \times 14 \mathrm{~cm})$ during the entire experimental procedure. OF1 adult mice (Charles River, France) were used as aggressive opponents $(N=20)$ and were individually housed in plastic cages $(21 \times 32 \times 20 \mathrm{~cm})$ for at least a month prior to initiation of the experiments in order to heighten aggression (Rodríguez-Arias et al., 1998). All mice were housed in controlled laboratory conditions: constant temperature and humidity, and a reversed light schedule (white light from 8:00 to 20:00). Food and water were available ad libitum to all the mice used in this study, except during behavioral tests. All procedures were conducted in compliance with the guidelines of the European Council Directive 2010/63/UE regulating animal research and were approved by the local ethics committees of the University of Valencia and the UPF/PRBB, respectively.

\subsection{Drugs}

To establish CPP, animals were injected i.p. with a dose of $1.5 \mathrm{mg} /$ $\mathrm{kg}$ of cocaine hydrochloride (Alcaliber laboratory, Spain) in a volume of $0.01 \mathrm{ml} / \mathrm{g}$ of weight. This dose of cocaine was selected on the basis of previous CPP studies showing that doses below $3 \mathrm{mg} / \mathrm{kg}$ are subthreshold (Arenas et al., 2014; Montagud-Romero et al., 2017; VidalInfer et al., 2012). For self-administration studies, a dose of $0.5 \mathrm{mg} / \mathrm{kg}$ / infusion of cocaine (Alcaliber laboratory, Spain) was available during the acquisition phase. All i.p. administrations were adjusted in a volume of $0.01 \mathrm{ml} / \mathrm{g}$ of body weight. Physiological saline $(\mathrm{NaCl} 0.9 \%)$ was used to dissolve cocaine.

\subsection{Experimental design}

In this study, three different cohorts of mice were employed, all of which were exposed to the SD procedure or exploration from PND 54 to 63. $24 \mathrm{~h}$ after the last SD episode, all the animals performed the social withdrawal test to evaluate depressive-like behaviors and were characterized as resilient (R) or susceptible (S) depending on their social withdrawal ratio (SWR). In the 1st cohort of mice, brain and blood samples were taken 3 days after the social withdrawal test (PND 67) (Control $n=15$; R $\mathrm{n}=15$; and $\mathrm{S} n=14$ ). In the 2 nd cohort of mice, after 3 weeks being undisturbed in their home cages, mice underwent the CPP procedure (PND 83) with $1.5 \mathrm{mg} / \mathrm{kg}$ of cocaine (Control $n=9$; $\mathrm{R} n=12$; and $\mathrm{S} n=17$ ). Brain and blood samples were taken at the 
PND \begin{tabular}{|c|}
$1^{\text {st }}$ \\
cohort \\
Brain/ \\
Blood
\end{tabular}

PND

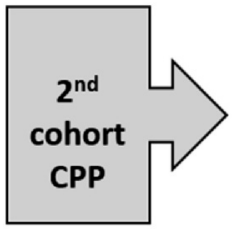

PND

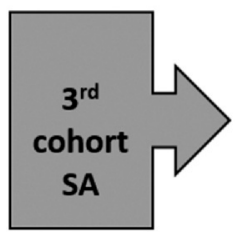

$54-57-60-63$

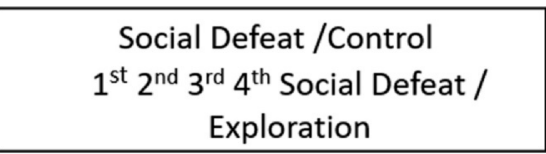

$54-57-60-63$

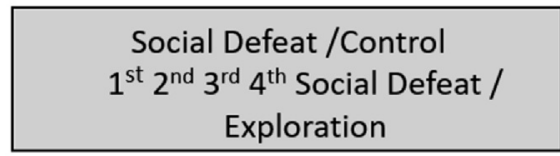

$54-57-60-63$

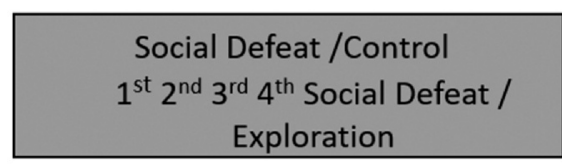

64

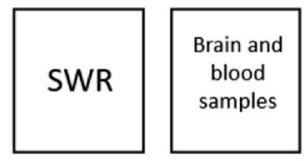

64

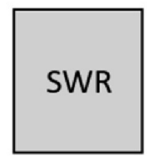

64

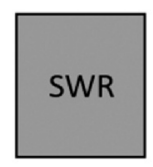

67

Fig. 1. Experimental design.

end of this procedure (PND 93). The 3rd cohort of mice initiated the SA procedure on PND 83 to 100 (Control $n=11 ; \mathrm{R} n=19$; and $\mathrm{S} \mathrm{n}=12$ ).

The experimental design is depicted in Fig. 1.

\subsection{Procedure and apparatus}

\subsubsection{Procedure of social defeat (SD)}

Animals in the stress/defeated groups were exposed to 4 episodes of SD during adulthood, each lasting $25 \mathrm{~min}$ and consisting of three phases. The initial phase began by introducing the "intruder" (the experimental animal) into the home cage of the "resident" (the aggressive opponent) for $10 \mathrm{~min}$ (Tornatzky and Miczek, 1993). During this initial phase, the intruder was protected from attack, but the wire mesh walls of the cage allowed for social interactions and species-typical threats from the male aggressive resident, thus facilitating instigation and provocation (Covington and Miczek, 2001). In the second phase, the wire mesh was removed from the cage to allow confrontation between the two animals over a 5-min period. Finally, the wire mesh was returned to the cage to separate the two animals once again for another $10 \mathrm{~min}$ to allow for social threats by the resident. The non-stressed exploration groups underwent the same protocol, but without the presence of a "resident" mouse in a clean cage. Intruder mice were exposed to a different aggressor mouse during each SD episode. The criterion used to define an animal as defeated was the adoption of a specific posture signifying defeat, characterized by an upright submissive position, limp forepaws, upwardly angled head, and retracted ears (Miczek et al., 1982; Rodríguez-Arias et al., 1998). All agonistic encounters of each SD protocol were videotaped to confirm social defeat of the intruder mice and to analyze ethologically the attack behaviors (duration and latency) of the resident mice. These behaviors were scored in resident mice and avoidance/flee, and defensive/submissive behaviors were evaluated in intruder mice. A detailed description of these behaviors can be found in Rodríguez-Arias et al., 1998.

\subsubsection{Social withdrawal ratio (SWR)}

The social withdrawal ratio used was based on the social approachavoidance test previously described by Berton et al. (2006). The test took place $24 \mathrm{~h}$ after the last social defeat during daylight and in a different environment of the confrontation sessions. First, animals were transferred to a quiet, dimly lit room $1 \mathrm{~h}$ before the test was initiated. After habituation, each animal was placed in the center of a square arena (white Plexiglas open field, $30 \mathrm{~cm}$ on each side and $35 \mathrm{~cm}$ high) and its behavior was monitored by video (EthoVision XT 11, $50 \mathrm{fps}$; camera placed above the arena). Animals were allowed to explore the arena twice, for $600 \mathrm{~s}$ in each session, during two different experimental sessions. In the first (object session), an empty perforated Plexiglas cage $(10 \times 6.5 \times 35 \mathrm{~cm})$ was placed in the middle of one wall of the arena. In the second session (social session), an unfamiliar C57BL/6 male mouse was introduced into the cage as a social stimulus. Although it can be argued that the probe mouse used in the social interaction test resembles the aggressor, and that this could foster social aversion, this is unlikely, since previous experiments demonstrate similar amounts of social investigation, irrespective of the strain used (i.e., C57BL/6; Berton et al., 2006). Before each session, the arena was cleaned with $5 \%$ alcohol solution to minimize odor cues. Between sessions, the experimental mouse was removed from the arena and returned to its home cage for $2 \mathrm{~min}$.

Locomotion and arena occupancy during object and social sessions were determined using the animals' horizontal position, determined by commercial video tracking software (EthoVision XT 11, Noldus). Conventional measures of arena occupancy, like time spent in the interaction zone and corners, were quantified. The former is commonly used as social preference-avoidance score and is calculated by measuring the time spent in a $6.5 \mathrm{~cm}$ wide corridor surrounding the restraining cage. Corners were defined as two squares of similar areas on the opposite wall of the arena.

\subsubsection{Conditioned place preference (CPP)}

For place conditioning, we employed eight identical Plexiglas boxes with two equally sized compartments $(30.7 \mathrm{~cm}$ long $\times 31.5 \mathrm{~cm}$ wide $\times 34.5 \mathrm{~cm}$ high) separated by a gray central area $(13.8 \mathrm{~cm}$ long $\times 31.5 \mathrm{~cm}$ wide $\times 34.5 \mathrm{~cm}$ high). The compartments had different colored walls (black vs white) and distinct floor textures (fine grid in the black compartment and wide grid in the white one). Four infrared light beams in each compartment of the box and six in the central area allowed the position of the animals and their crossings from one compartment to the other to be recorded. The equipment was controlled by three computers using MONPRE 2Z software (CIBERTEC, SA, Spain). 
Place conditioning, consisting of three phases, was carried out during the dark cycle following a procedure that was unbiased in terms of initial spontaneous preference (Manzanedo et al., 2001). During the first phase - or preconditioning (Pre-C) - mice were allowed access to both compartments of the apparatus for 900 s per day on 3 consecutive days. On day 3 , the time spent in each compartment was recorded. Animals showing a strong unconditioned aversion $(<33 \%$ of session time; i.e. $250 \mathrm{~s}$ ) or preference ( $>67 \%$ of the session time; i.e. $650 \mathrm{~s}$ ) for any compartment were discarded from the rest of the study. In this study, 4 mice were discarded. During the conditioning phase, half of the animals in each group received the drug or vehicle in one compartment, while the other half received it in the other compartment. In the second phase (conditioning), which lasted 4 days, animals were conditioned with $1.5 \mathrm{mg} / \mathrm{kg}$ cocaine or saline. An injection of physiological saline was administered before confining the mice to the vehicle-paired compartment for $30 \mathrm{~min}$. After an interval of $4 \mathrm{~h}$, the animals received cocaine immediately prior to confinement to the drug-paired compartment for a further $30 \mathrm{~min}$. The central area was made inaccessible by guillotine doors during conditioning. The dose of cocaine used during conditioning phase was a subthreshold dose $(1.5 \mathrm{mg} / \mathrm{kg}$, proven not to be effective in controls) in order to evaluate increased sensitivity to the conditioned rewarding effects of cocaine. In the third phase - or postconditioning (Post-C) -, which took place on day 8, the guillotine doors separating the two compartments were removed and the time spent in each compartment by the untreated mice during a $900 \mathrm{~s} \mathrm{ob-}$ servation period was recorded. The difference in seconds between the time spent in the drug-paired compartment during the Post-C and the third Pre-C tests is a measure of the degree of conditioning induced by the drug (conditioning score).

\subsubsection{Operant cocaine self-administration (SA)}

2.4.4.1. Apparatus

2.4.4.1.1. Operant self-administration chambers. For SA procedures, we used ten mouse operant chambers (Model ENV-307A-CT, Med Associates, Inc. CIBERTEC SA, Madrid, Spain) equipped with two holes; one was selected as the active hole for delivering the reinforcer and the other as the inactive hole. Active and inactive nose-pokes holes were assigned randomly. Nose-poking in the active hole resulted in a reinforcer (cocaine $0.5 \mathrm{mg} / \mathrm{kg} /$ infusion), while nose-poking in the inactive hole had no consequences. Cocaine was delivered over $2 \mathrm{~s}$ in the form of a $20 \mu \mathrm{lL}$ injection via a syringe mounted on a microinfusion pump (PHM-100A, Med-Associates, Georgia, VT, USA) connected via Tygon tubing $(0.96 \mathrm{~mm}$ outer diameter, Portex Fine Bore Polythene Tubing, Portex Limited, UK) to a single-channel liquid swivel (375/25, Instech Laboratories, Plymouth Meeting, PA, USA) and the mouse's intravenous catheter. A light located above the active hole was paired contingently with the delivery of the reinforcer. The chambers were housed in sound- and light-attenuated boxes equipped with fans to provide ventilation and white noise.

\subsubsection{Procedures}

2.4.4.2.1. Surgery. Surgical implantation of the catheter into the jugular vein was performed under isoflurane anaesthesia (1.5-2.0\%). Meloxicam (0.5 mg/kg s.c.; Metacam ${ }^{\circledR}$, Barcelona, Spain) and enrofloxacin (7.5 mg/kg i.p.; Baytril ${ }^{\circledR} 2.5 \%$; Barcelona, Spain) were injected after the surgery. The home cages were placed on thermal blankets to avoid post-anaesthesia hypothermia. Mice were weighed daily and treated with meloxicam for $48 \mathrm{~h}$. The animals were allowed to recover for at least three days before the acquisition phase began.

2.4.4.2.2. Acquisition of operant cocaine SA. SA experiments were conducted as described in Soria et al. (2008). Mice were trained for $2 \mathrm{~h}$ per day to nose-poke in order to receive a $0.5 \mathrm{mg} / \mathrm{kg} /$ infusion of cocaine on 10 consecutive days, under a fixed ratio of 1 (FR1). Sessions began with a cocaine priming infusion. When mice responded at the active hole, the stimulus light lit up for $4 \mathrm{~s}$ and a cocaine infusion was delivered automatically. Each infusion was followed by a 15-s time-out period in which a nose-poke through the active hole had no consequences. Mice were considered to have acquired stable selfadministration behavior when the following criteria were met in 2 consecutive FR1 sessions: (i) $80 \%$ stability in reinforcements (the number of reinforcers in each day deviated by $<20 \%$ from the mean number of reinforcers on the 2 consecutive days); (ii) $\geq 65 \%$ of responses were received at the active hole; and (iii) a minimum of 5 infusions per session. The acquisition phase lasted 10 days for all animals, regardless of the day of acquisition. Mice underwent the PR test $24 \mathrm{~h}$ after the last day of acquisition. The PR test consisted of a single-session test that lasted $2 \mathrm{~h}$. In this session, the response requirement to earn an infusion escalated according to the following series: 1-2-3-5-12-18-27-40-60-90-135-200-300-450-675-1000. The breaking point is the last ratio reached by each animal, which is considered the highest effort the mouse is willing to make in order to obtain an infusion. In this study, one mouse was discarded because it failed to achieve acquisition criteria.

\subsubsection{Tissue sampling for biochemical analyses}

A total number of 90 mice, 46 from the 1st cohort after Post-C and 44 from the 2nd cohort after the social withdrawal test, were sacrificed by cervical dislocation in order to collect biological samples. For corticosterone analyses blood samples were collected from tail vein into heparin tubes (Microvette CB 300, Sarstedt) $30 \mathrm{~min}$ after social defeat and the plasma was stored at $-80{ }^{\circ} \mathrm{C}$. Brains were immediately removed from the skull and placed in an ice-cold plaque. Cerebellum and olfactory bulbs were eliminated, and the brain areas of interest - the striatum (STR) and hippocampus (HPC) - were dissected following the procedure described by Heffner et al. (1980). Brain tissue samples were then frozen on dry ice and stored immediately at $-80{ }^{\circ} \mathrm{C}$ until the CX3CL1 and IL-6 assays were performed.

\subsubsection{Immunoassay analysis (ELISA)}

Blood and brain samples from mice belonging to the 1st (PND 93) and 2nd (PND 67) cohorts of mice were analyzed. Neuroinflammatory markers were not analyzed in animals experiencing SA, since an increase of these markers could have been due to the surgical procedure. Frozen mouse samples of STR and HPC were homogenized $0.5 \mathrm{mg}$ tissue/ $\mu \mathrm{L}$ ) in cold lysis buffer (1\% Nonidet P-40, $20 \mathrm{mM}$ Tris-HCl pH 8, $130 \mathrm{mM} \mathrm{NaCl}, 10 \mathrm{mM} \mathrm{NaF}, 10 \mathrm{~g} / \mathrm{ml}$ aprotinin, $10 \mathrm{~g} / \mathrm{ml}$ leupeptin, $10 \mathrm{mM}$ DTT, $1 \mathrm{mM} \mathrm{Na}_{3} \mathrm{VO}_{4}$ and $1 \mathrm{mM}$ PMSF). The concentrations of CX3CL1 and IL-6 in homogenized extracts were measured with commercial enzyme-linked immunosorbent assay (ELISA) kits in 96-well strip plates (Abcam, ab100683, ab100712). We determined CX3CL1 concentration in STR and HPC, and IL-6 concentration in STR, HPC and plasma samples. All reagents and standard dilutions were prepared following the manufacturer's instructions. To determine absorbance, we employed an iMark microplate reader (Bio-RAD) controlled by Microplate Manager 6.2 software. Optical density of plates was read at $450 \mathrm{~nm}$ and the final results were calculated using a standard curve following the manufacturer's instructions. Total protein concentrations were determined using the Pierce BCA Protein Assay Kit (ThermoFisher Scientific) to determine the number of nanograms of CX3CL1 and picograms of IL-6. Data are expressed as $\mathrm{ng} / \mathrm{mg}$ or $\mathrm{pg} / \mathrm{mg}$ of protein for tissue samples.

\subsection{Statistical analysis}

Mice were previously classified into $\mathrm{R}$ and $\mathrm{S}$ groups based on the SWR and these data were analyzed by one-way ANOVA with a betweensubjects variable - Stress, with three levels (Control, S and R). SWR is calculated by considering the time spent by an experimental mouse in the interaction zone when a social target is present divided by the time it spends in the interaction zone when the target is absent. A ratio equal to 1 means that equal time has been spent in the presence versus absence of a social target. Based on the regular behavior of control 
C57BL/6 mice, animals with a ratio under 1 are classified as $\mathrm{S}$, while those with a ratio equal to or higher than 1 are classified as $\mathrm{R}$ (Golden et al., 2011).

The data of the time that experimental mice and their aggressive opponents spent engaged in different behavioral categories during the SD episodes were compared by means of a mixed two-way ANOVA with one between-subject variable Stress, with two levels (R and S); and one within subject variable Days, with two levels (1st and 4th SD). To evaluate the CPP induced by $1.5 \mathrm{mg} / \mathrm{kg}$ of cocaine, the conditioning scores were analyzed with one-way ANOVA with a between-subjects variable - Stress, with three levels (Control, S and R). For the cocaine self-administration curve, we used a three-way ANOVA analysis with day of training and hole (active vs inactive) as within-subject variables and Stress (Control, S and R) as a between-subject variable. For the analysis of day of acquisition, total intake and breaking point, we used a one-way ANOVA, with a between-subjects variable - Stress, with three levels. For the analysis of total nose-pokes of the progressive ratio test, we used a two-way ANOVA, with a within-subject variable hole (active vs inactive) and Stress (Control, $\mathrm{S}$ and $\mathrm{R}$ ) as a between-subject variable.

The data of the CX3CL1 and IL-6 levels in STR and HPC from mice in the 1st and 3rd cohorts were analyzed using a one-way ANOVA with one between-subjects variable - Stress, with three levels (Control, S and R). When necessary, a two-way ANOVA with the variables Stress and Cohort (1st and 2nd) was also employed.

In all the studies, following the ANOVA, Bonferroni post-hoc tests were calculated whenever required. All statistical analyses were performed using SPSS Statistics v.26. Data were expressed as mean \pm SEM and a value of $p<0.05$ was considered statistically significant.

\section{Results}

\subsection{Susceptible mice have lower social withdrawal ratio than their resilient counterparts}

The ANOVA of the SWR performed after the last SD (see Fig. 2) in the three cohorts of mice showed an effect of the variable Stress [F $(2,44)=13.489 ; p<0.001],[\mathrm{F}(2,38)=7.796 ; p<0.002]$, and $[\mathrm{F}$ $(2,40)=13.381 ; \mathrm{p}<0.001]$ respectively. The post-hoc comparison revealed lower social scores among $S$ mice in comparison with $R$ ( $\mathrm{p}<0.001$ in all cases) and control animals $(\mathrm{p}<0.001$ for the 1 st cohort of mice and $p<0.01$ for the 3rd cohort of mice).

\subsection{Susceptible mice showed passive-reactive coping during social defeat}

The ANOVA for the time employed in Avoidance/Flee behaviors (Fig. 3a) by defeated mice divided into R or S according to their SWR showed an effect of the interaction Days $\mathrm{X}$ Stress for the first $[\mathrm{F}$ $(1,27)=5.276 ; p<0.03]$ and second cohorts $[\mathrm{F}(1,27)=4.406$; $p<0.04]$. During the first social defeat, $\mathrm{S}$ mice spent more time engaged in these behaviors than their R counterparts $(p<0.05$ in both cases). Moreover, $\mathrm{R}$ mice significantly increased the time spent in these behaviors, an effect that was not observed in $S$ animals $(p<0.01$ fourth SD with respect first SD). In the third cohort of mice, there was an effect of the variable Stress $[\mathrm{F}(1,27)=14.023 ; p<0.001]$, with $S$ mice spending more time in these behaviors than $\mathrm{R}$ animals $(p<0.01)$.

The ANOVA for the time employed in Submissive/Defensive behaviors (Fig. 3b) by defeated mice divided into $\mathrm{R}$ or $\mathrm{S}$ according to their SWR showed an effect of Stress for the first $[\mathrm{F}(1,27)=10.976$; $p<0.003]$ and second cohorts $[\mathrm{F}(1,27)=7.223$; $\mathrm{p}<0.01]$. S mice spent more time engaged in these behaviors than their $\mathrm{R}$ counterparts ( $\mathrm{p}<0.01$ in both cases). Moreover, in the third cohort there was a significant effect of the interaction Days X Stress $[F(1,27)=23.213$; $\mathrm{p}<0.001$ ). $\mathrm{S}$ mice spent more time in these behaviors than $\mathrm{R}$ mice only during the first SD ( $p<0.001$ ). Moreover, only $\mathrm{R}$ mice in the third cohort increased the time spent in defensive/submissive behavior $(p<0.01$ in the 4th SD with respect the 1st).

\subsection{Susceptible mice showed higher conditioning score than resilient animals}

The ANOVA showed no significant differences between the time spent in the drug-paired and vehicle-paired compartments during the Pre-C phase $(F(1,37)=1720, p=0.198)$. Once the animals had been divided into R and S groups depending on their SWR (Fig. 4), the ANOVA of the Conditioning Score showed an effect of the variable Stress $[\mathrm{F}(2,38)=6.016 ; p<0.006]$, with $\mathrm{S}$ animals showing a significantly higher conditioning score than $\mathrm{R}(\mathrm{p}<0.01)$.

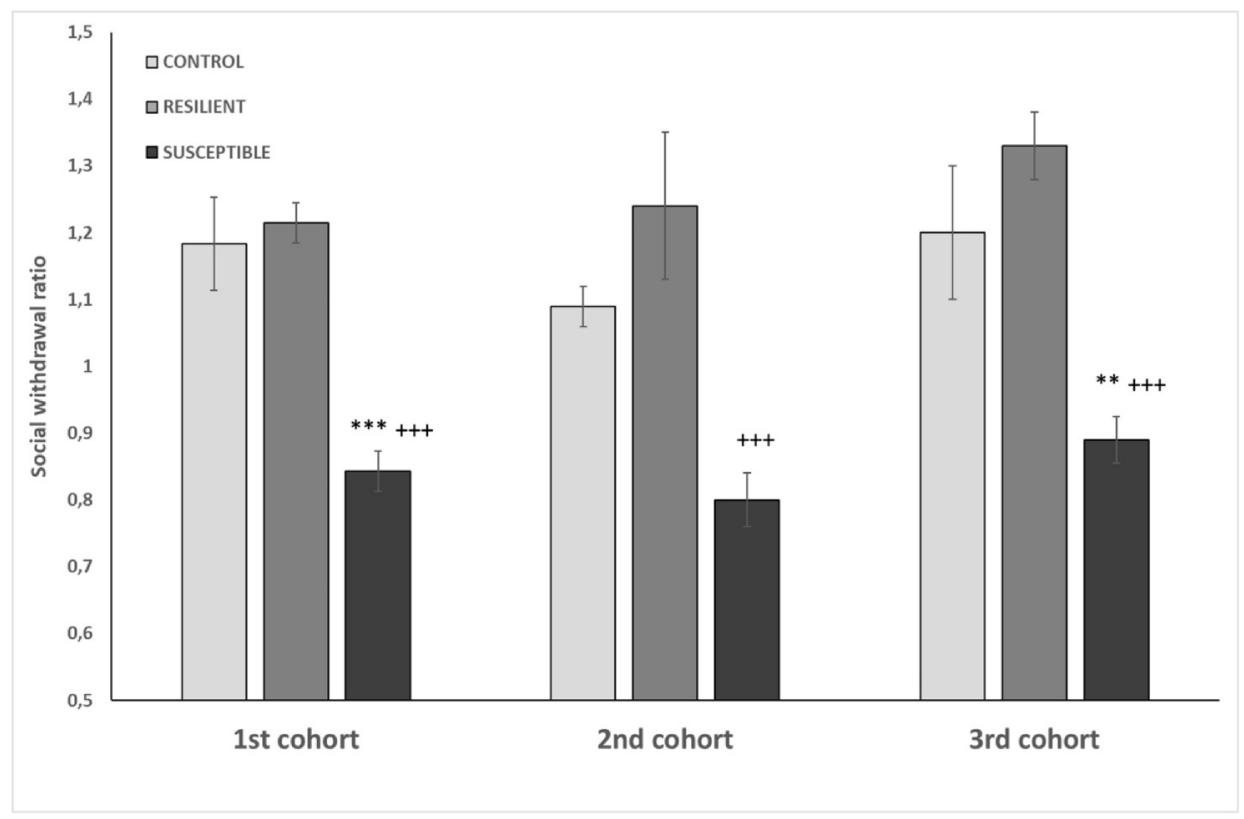

Fig. 2. Effect of repeated SD on SWR in C57BL/6 male mice. The bars represent the mean of the time spent in the social session/object session in the interaction zone and the vertical lines \pm SEM. Values $>1$ indicate preference for social interaction and $<1$ indicates social avoidance (Golden et al., 2011). Mice were divided into Control $(n=15), \mathrm{R}(\mathrm{n}=15)$ and $\mathrm{S}$ $(n=14)$ in the first cohort; Control $(n=9)$, R $(n=12)$ and $\mathrm{S}(n=17)$ in the second cohort; and Control $(n=11), \mathrm{R}(n=19)$ and $\mathrm{S}(\mathrm{n}=12)$ in the third cohort. Bonferroni post-hoc test **** $p<0.001 * * p<0.01$, significant difference compared to the Control group; +++ $\mathrm{p}<0.001$, significant difference compared to the $\mathrm{R}$ group. 


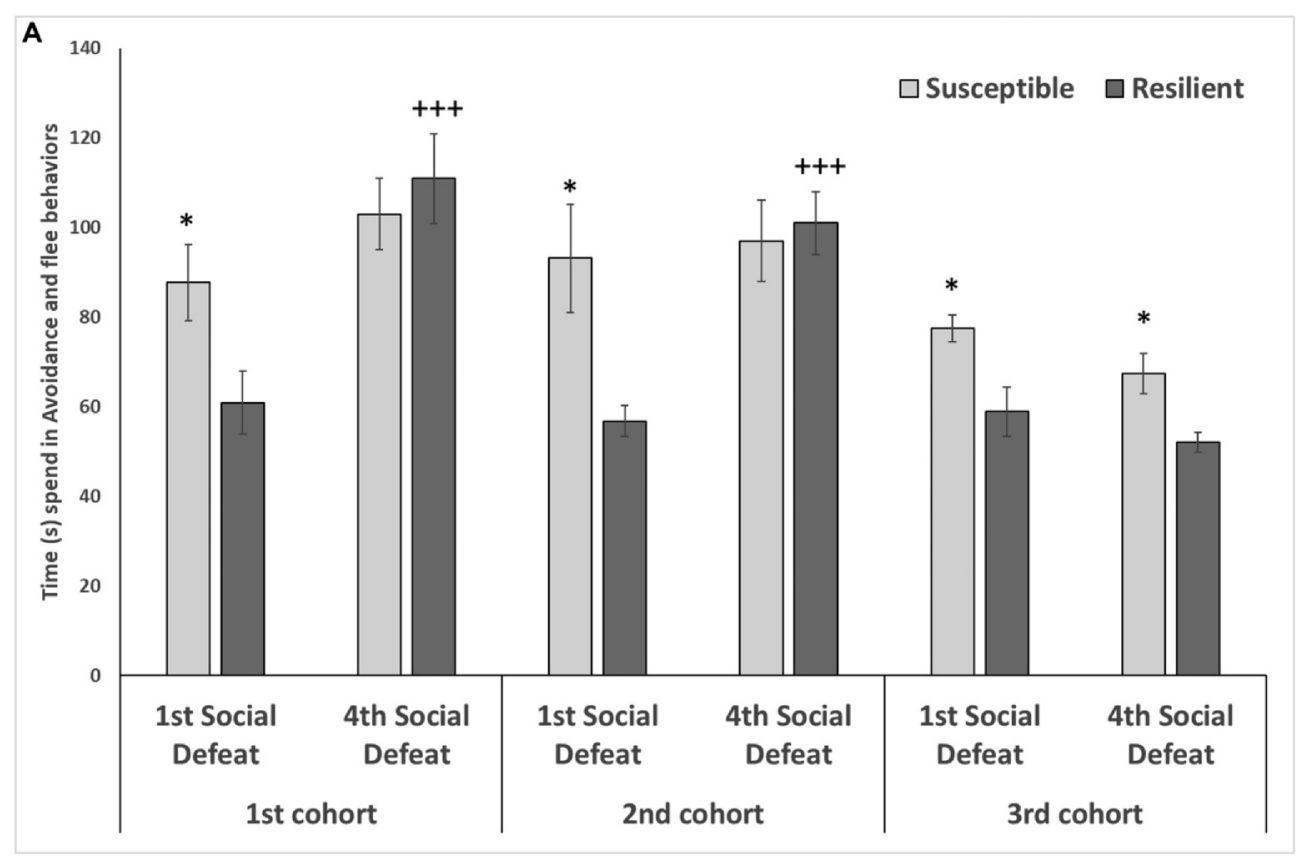

Fig. 3. Coping behavior during SD. Bars represent the mean of the time spent in Avoidance /Flee (a) and Submissive /defensive (b) behaviors during the 1st and 4th SD /light gray for Susceptible and dark gray for Resilient) and the vertical lines \pm SEM. Mice were divided into R $(n=15)$ and S $(n=14)$ in the 1st cohort; into R $(n=12)$ and $\mathrm{S}(n=17)$ in the 2 nd cohort; and into $\mathrm{R}(n=19)$ and $\mathrm{S}(\mathrm{n}=12)$ in the 3rd cohort. Bonferroni post-hoc test * $\mathrm{p}<0.05, * * p<0.01, * * * *<0.001$ significant difference compared to $\mathrm{R}$ group; $++\mathrm{p}<0.01,+++\mathrm{p}<0.001$ with respect 1st SD.

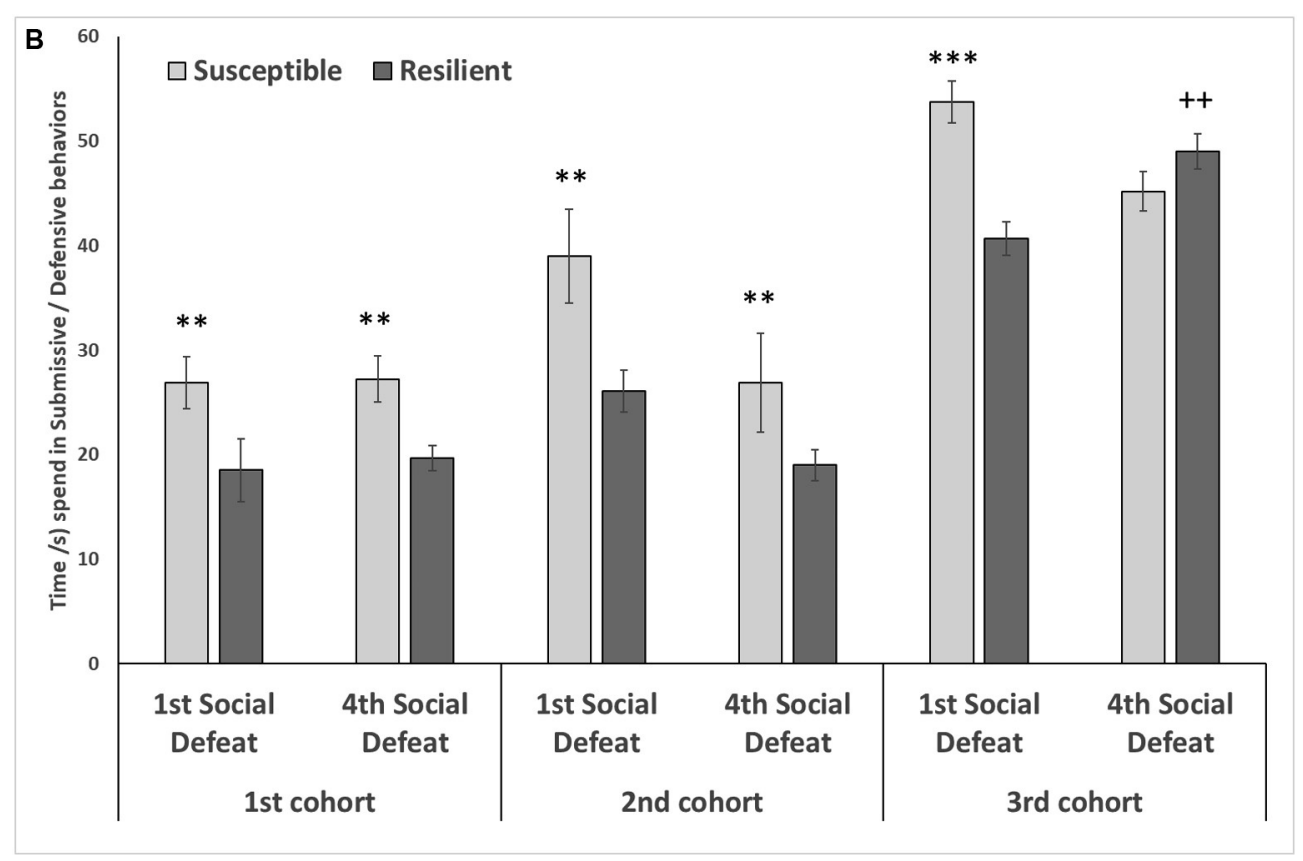

Fig. 3. (continued)

\subsection{Susceptible mice took more cocaine infusions in self-administration}

Defeated animals were divided into $\mathrm{R}$ and $\mathrm{S}$ groups according to the score obtained in SWR in order to undergo the cocaine SA (Fig. 5). A three-way ANOVA for the acquisition curve showed a main effect of Day of training $[\mathrm{F}(9,39)=14.05 ; p<0.001]$, Stress $[\mathrm{F}$ $(1,44)=118.689 ; \mathrm{p}<0.001]$ and Hole $[\mathrm{F}(1,44)=118.689$ $\mathrm{p}<0.001]$, with interaction between Day of training and Hole [F $(9,36)=7.849 ; \mathrm{p}<0.001]$, and with a tendency in the interaction between Stress and Hole $[\mathrm{F}(2,78)=2.905 ; p=0.061]$. Post-hoc analysis for Stress and Hole interaction showed that resilient and susceptible groups of mice behaved differently over the days for the active ( $\mathrm{p}<0.01$ ), but not for the inactive hole.

A one-way ANOVA for Day of acquisition revealed no significant differences among the groups.

One-way ANOVA for total intake revealed a main effect of Stress [F $(2,39)=3,57 ; p<0.05]$, revealing that the three groups of animals (control, R and S) behaved differently, and particularly R versus $\mathrm{S}$ as indicated the post-hoc analysis $(\mathrm{p}<0.05)$. These data show that $\mathrm{R}$ mice self-administered less cocaine as compared to $\mathrm{S}$ mice.

Regarding the progressive ratio schedule of reinforcement, a twoway ANOVA for total nose-pokes showed a main effect for Hole [F 


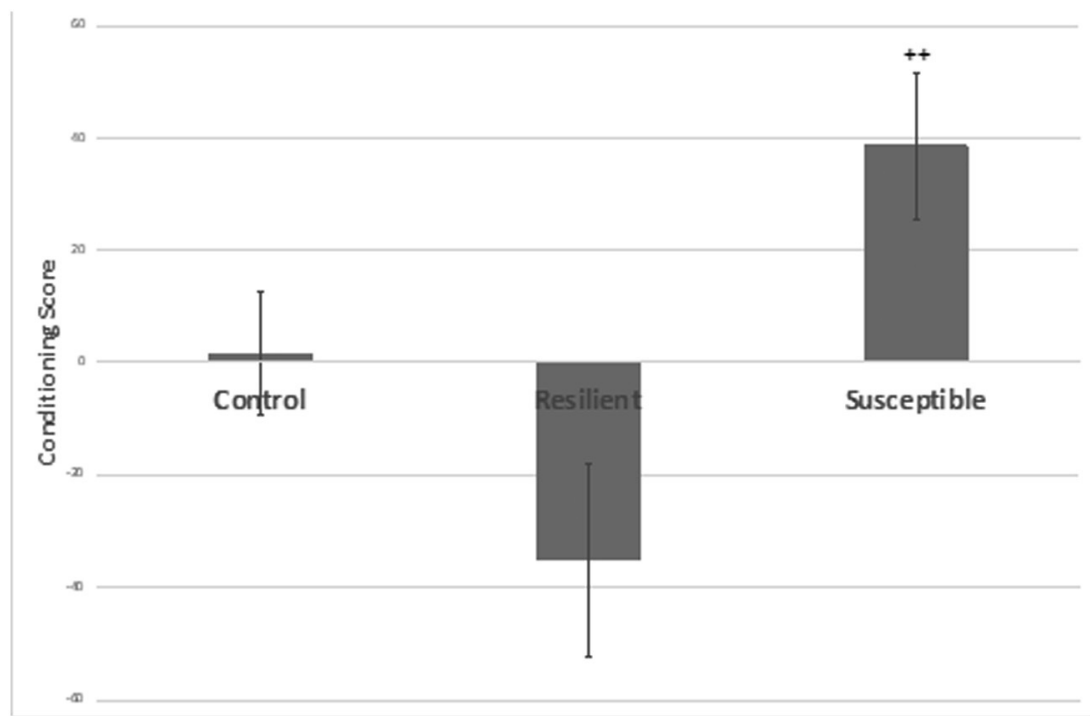

$(1,78)=52.12 ; p<0.001]$, but none for Group or Interaction between groups. A one-way ANOVA calculated for the breaking point revealed no significant differences due to the variable Group $(\mathrm{p}=0,0633)$.

\subsection{Susceptible mice showed higher levels of the pro-inflammatory cytokine} IL-6

The ANOVA for the striatal IL- 6 levels showed an effect of the variable Stress for the 1 st cohort of mice $[\mathrm{F}(2,42)=4.214 ; p<0.022]$ (see Fig. 6a). Susceptible mice displayed higher IL-6 levels than the control animals $(p<0.05)$, without differences with $\mathrm{R}$ animals. Although $S$ mice showed higher IL-6 levels, no significant differences were observed in the striatal IL-6 levels in the 2nd cohort of mice, probably due to the elevated variance of the results.

The ANOVA for the hippocampal IL-6 levels showed an effect of the variable Stress for the 1 st $[\mathrm{F}(2,44)=3.389 ; p<0.045]$ and the 2nd cohort of mice $[\mathrm{F}(2,38)=4.000 ; p<0.027]$ (see Fig. 6b). Susceptible mice displayed higher IL- 6 levels than the control animals ( $\mathrm{p}<0.05$ in both cases), without differences with $\mathrm{R}$ animals.

The ANOVA of striatal CX3CL1 levels revealed a significant effect of the variable Stress $[\mathrm{F}(2,44)=8.556 ; p<0.001]$ (see Fig. $7 \mathrm{a}$ ) in the
Fig. 4. Effect of repeated SD on the conditioning score induced by $1.5 \mathrm{mg} / \mathrm{kg}$ of cocaine in C57BL/6 male mice. Bars represent the mean of the difference in time (s) spent in the compartment associated with the drug before and after conditioning sessions (conditioning score) and the vertical lines \pm SEM. Mice were divided into Control $(\mathrm{n}=15) ; \mathrm{R}$ $(n=15)$ and $S(n=14)$ in the 1 st cohort. Mice were characterized as $\mathrm{R}$ or $\mathrm{S}$ depending on their SWR. Bonferroni posthoc test $++p<0.01$, significant difference compared to $R$, Bonferroni test.

\section{A \\ Acquisition}

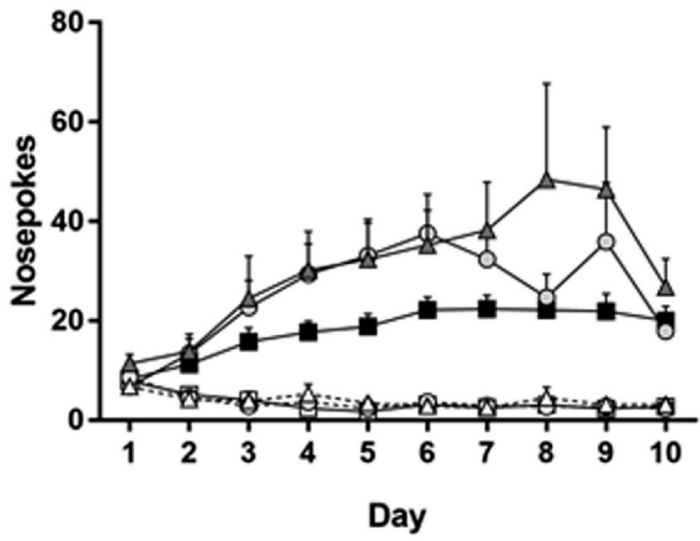

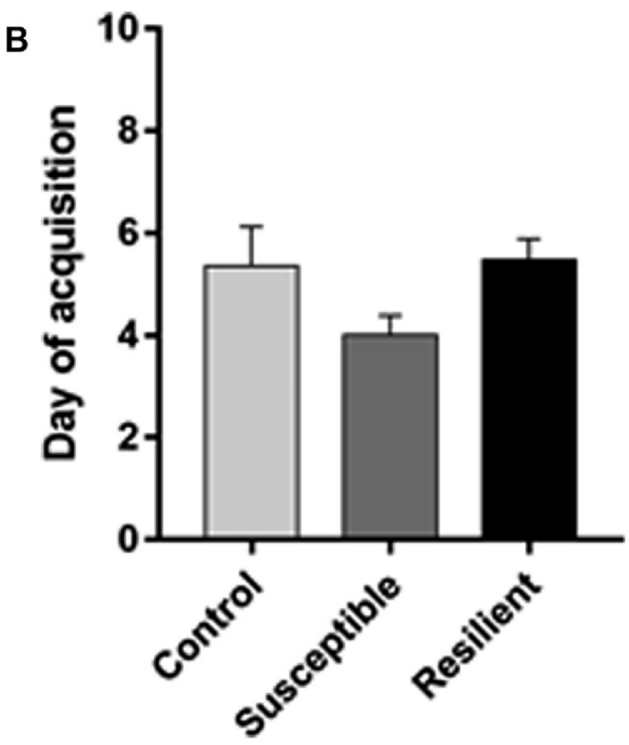

Fig. 5. (continued)

\section{-o- Control-Active \\ -o. Control-Inactive \\ $\triangle$ Susceptible-Active \\ $\cdot \Delta \cdot$ Susceptible-Inactive \\ $-\square-$ Resilient-Inactive \\ Resilient-Active}

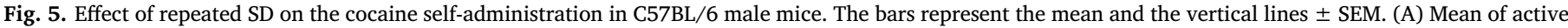

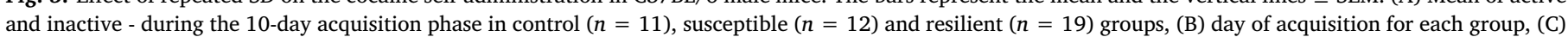

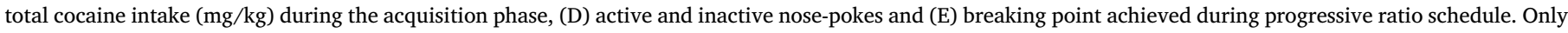
animals who acquired SA are shown. Data are expressed as mean + SEM. 


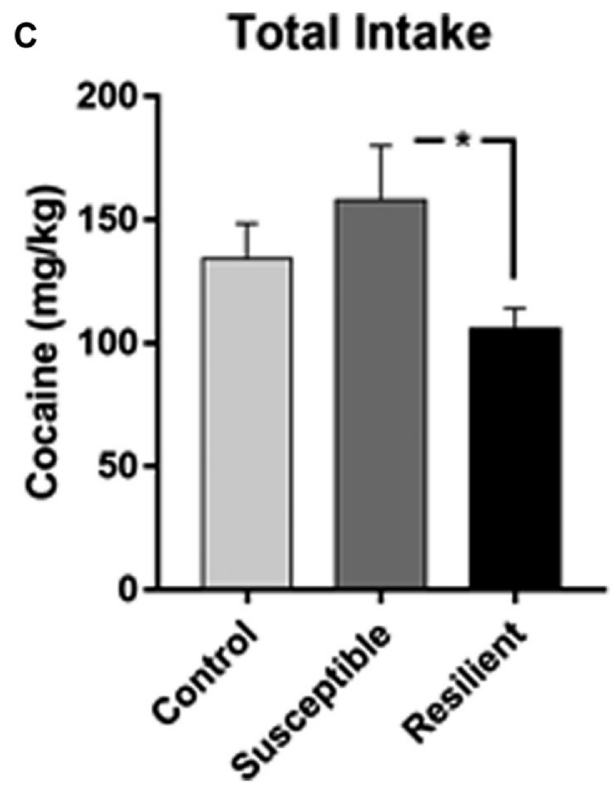

Fig. 5. (continued)

\section{Progressive ratio}

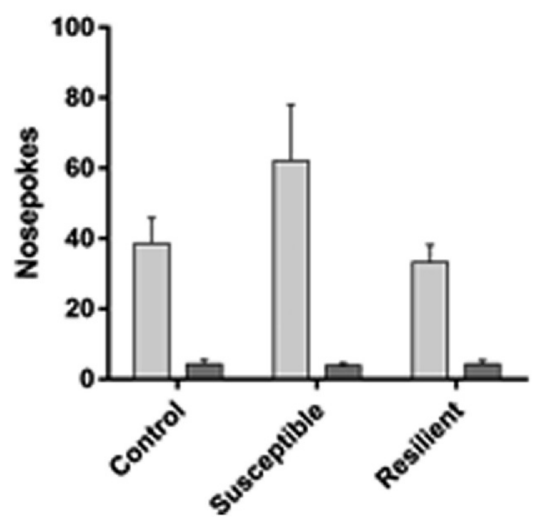

Fig. 5. (continued)
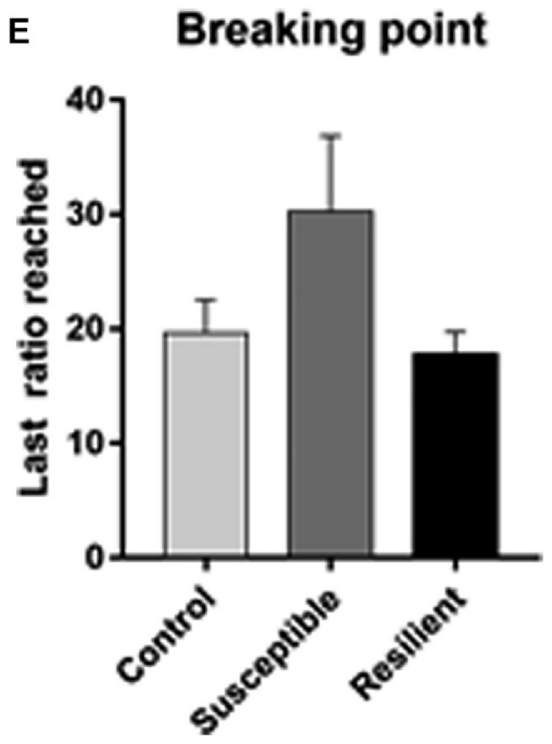

Fig. 5. (continued) 1st cohort of mice. Striatal CX3CL1 levels were lower among all defeated animals (either R or S) in comparison with controls $(p<0.01$ for $\mathrm{R}$ and $p<0.001$ for $\mathrm{S}$ ). No differences were observed in striatal CX3CL1 levels in the 2nd cohort of mice. However, CX3CL1 levels were lower in this cohort of mice, maybe due to the cocaine exposure. An ANOVA of the data from both cohorts of mice showed an effect of the interaction Stress x Cohort $[\mathrm{F}(2,82)=8.080 ; p<0.001]$. Control animals that experienced cocaine-induced CPP showed lower CX3CL1 levels than controls of the 1st cohort of mice ( $p<0.001$ ).

The ANOVA of hippocampal CX3CL1 levels revealed a significant effect of the variable Stress $[\mathrm{F}(2,41)=5.751 ; p<0.007]$ (see Fig. 7b). Hippocampal CX3CL1 levels were lower among all defeated animals (either R or S) in comparison with controls ( $\mathrm{p}<0.01$ for $\mathrm{R}$ and $\mathrm{p}<0.05$ for $\mathrm{S}$ ). No differences were observed in striatal CX3CL1 levels in the second cohort of mice. However, CX3CL1 levels were lower in this cohort of mice, again possibly due to the cocaine exposure. An ANOVA of the data from both cohorts of mice showed an effect of the interaction Stress $x$ Cohort $[\mathrm{F}(2,79)=4.310 ; p<0.017]$. Control animal that experienced cocaine-induced CPP showed lower CX3CL1 levels than controls in the 1st cohort of mice ( $\mathrm{p}<0.01$ ).

\subsection{Social defeat increased plasmatic corticosterone in $R$ and $S$ mice}

Plasmatic corticosterone levels (Fig. 8) were determined in animals $30 \mathrm{~min}$ after the 1st and 4th social defeat episodes. $\mathrm{R}$ and $\mathrm{S}$ mice were characterized according to their SWR. The ANOVA revealed an effect of the variable Stress $[F(2,33)=12.115 ; \mathrm{p}<0.001]$. $\mathrm{R}$ and $\mathrm{S}$ defeated mice showed higher corticosterone levels than Control rodents after the 1 st and 4th social defeat ( $p<0.001$ in all cases).

\section{Discussion}

It is well known that exposure to repeated SD encounters induces a long-lasting increase in the motivational effects of cocaine. By means of several variations of the SD procedure, numerous studies carried out in our laboratory and by other groups have consistently demonstrated an increase in the rewarding effects of cocaine using the CPP paradigm (Montagud-Romero et al., 2015; Rodríguez-Arias et al., 2016; Rodríguez-Arias et al., 2017), as well as an increase of cocaine seeking in the SA paradigm in socially defeated animals (for example Boyson et al., 2014; Ferrer-Pérez et al., 2019; Quadros and Miczek, 2009; Yap et al., 2015). However, the behavioral and neurobiological effects of social stress are not manifested in all individuals equally. After being exposed to social stress, only some individuals show intense deficits, while others continue to function normally. Individuals that adapt and maintain their normal physiology and behavior after exposure to social stress are classified as resilient (Pfau and Russo, 2015).

To date, most studies have evaluated resilience to depressive- or anxiety-like behaviors, but few have explored factors mediating susceptibility or resilience to the increase in cocaine-induced reward brought on by social stress. In the present study, we have shown for the first time that the behavioral and neuroinflammatory phenotypic profile of stressed mice that allows susceptibility or resilience to depressive-like behavior is also a predictor of vulnerability to the increased cocaine reward. Our most important result is that animals that are resilient to depressive-like behaviors are also resistant to cocaine reward. Susceptible mice showed higher conditioning score in the CPP and more cocaine infusions in the SA procedures than resilient animals. Moreover, susceptible mice displayed greater changes in neuroinflammatory markers not only immediately after social defeat, but we have shown for the first time that this response remained even one month after the last SD, when the CPP procedure ended. We also confirmed that susceptible mice showed passive-reactive coping during social defeats. 


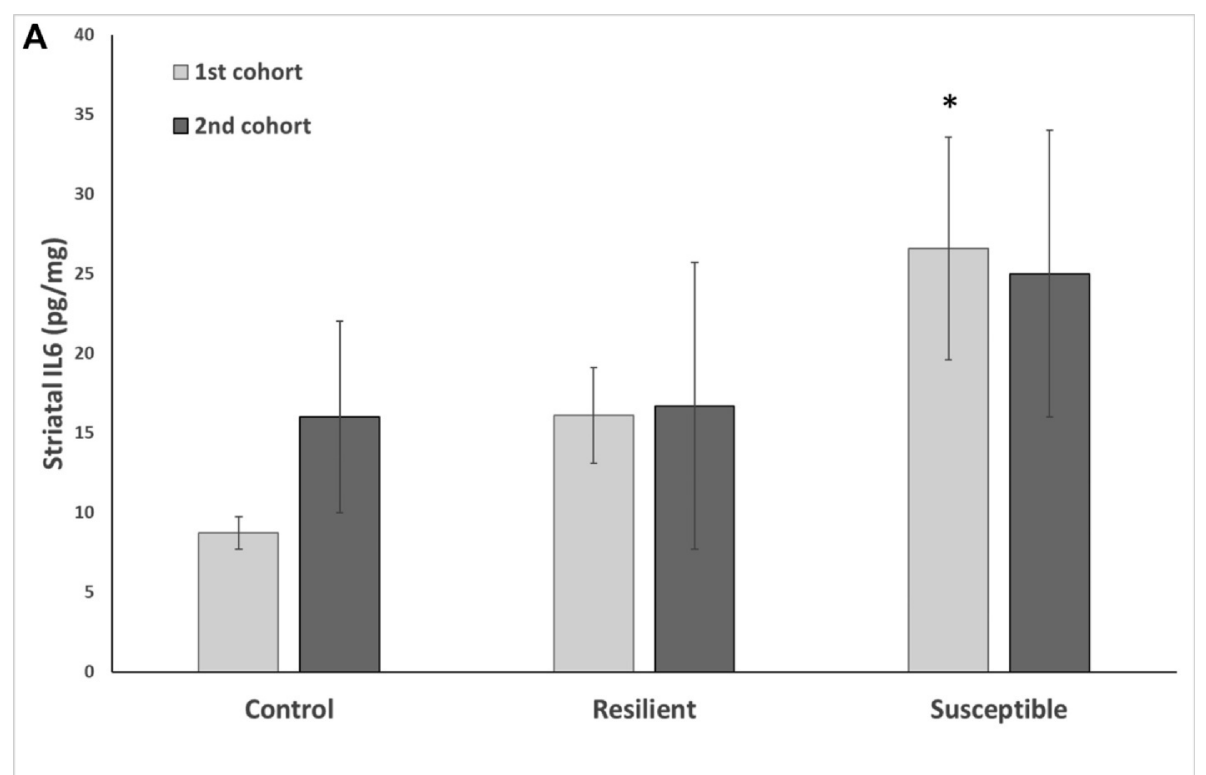

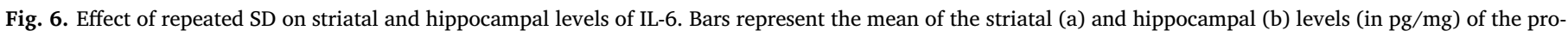

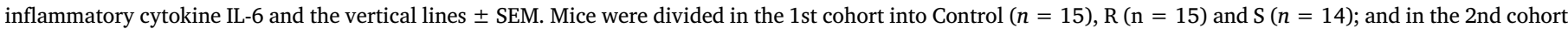
into Control $(n=9), \mathrm{R}(n=12)$ and $\mathrm{S}(n=17)$. Bonferroni post-hoc test $* p<0.05$, significant difference compared to Control group.

\subsection{Susceptibility or resilience to depressive-like behaviors and increase in cocaine reward induced by social defeat}

Numerous reports show that a depressive-like phenotype in rodents can be induced by repeated exposures to SD stress. Among other behaviors, defeated animals show anhedonia, anxiety and social avoidance (Berton et al., 2006; Kudryavtseva et al., 1991; Rygula et al., 2005). The response to the social interaction test performed $24 \mathrm{~h}$ after the last SD has been associated with resilience or susceptibility to stressinduced depressive-like behavior. Within this perspective, socially stressed mice that display social avoidance are considered susceptible. Healthy animals naturally engage in investigation of a social target, whereas the avoidance of social contact is considered to be a depressive-like behavior. Based on the behavior of control C57BL/6 mice, animals with a ratio under 1 are classified as susceptible, while those with a ratio equal to or higher than 1 are classified as resilient (Golden et al., 2011). According to this criterion, susceptible mice also show reduced sucrose preference, weight fluctuation and metabolic disturbances (Chuang et al., 2010). Interestingly, anxiety-like behavior, measured by the elevated plus maze or increased corticosterone release in response to stress, is observed in both resilient and susceptible animals (Krishnan et al., 2007).

We have previously shown that depending on their response to cocaine-conditioned effects, there are two different populations among the defeated mice (Ródenas-González et al., 2020). In that study, we showed that three weeks after the last episode of social stress, a susceptible group of mice showed a place preference for a sub-threshold dose of cocaine as a result of an increased response to cocaine. However, other defeated mice, the resilient group, did not develop preference for this dose of cocaine. In the present study, we have shown that susceptible mice that have increased response to cocaine also have greater depressive-like behaviors. Therefore, the susceptible or resilient

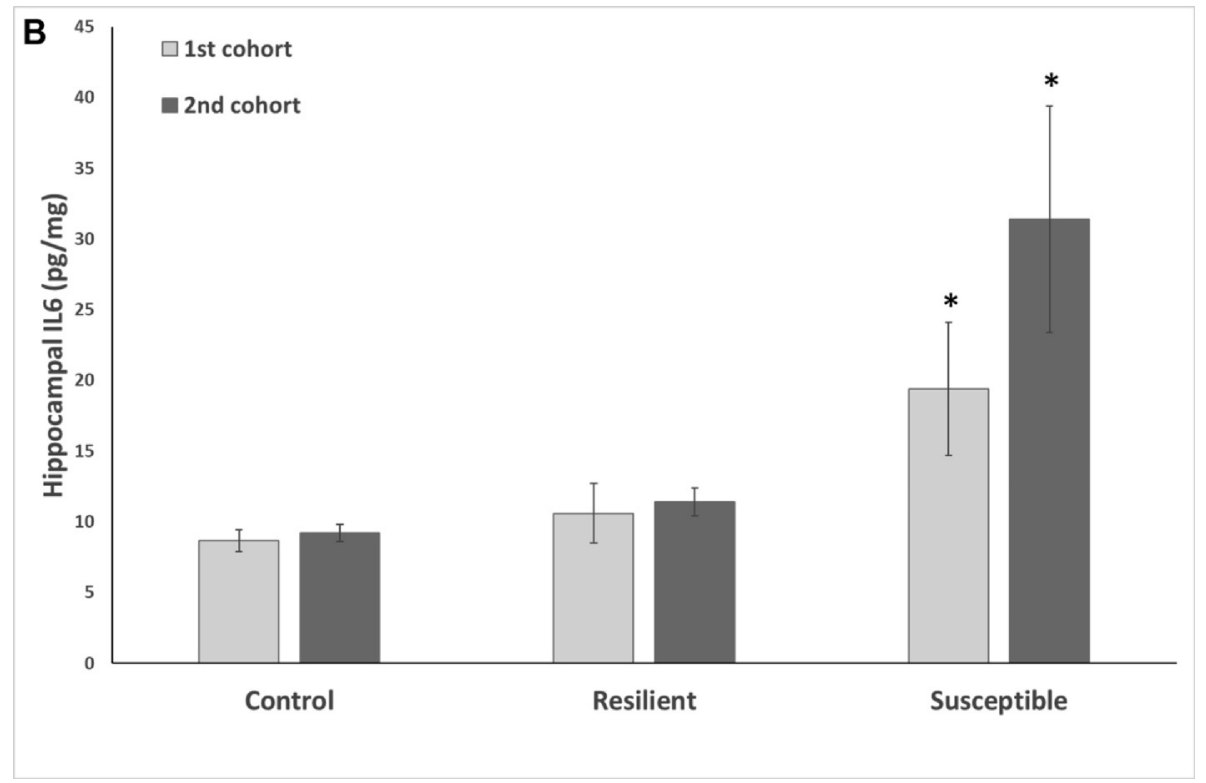

Fig. 6. (continued) 


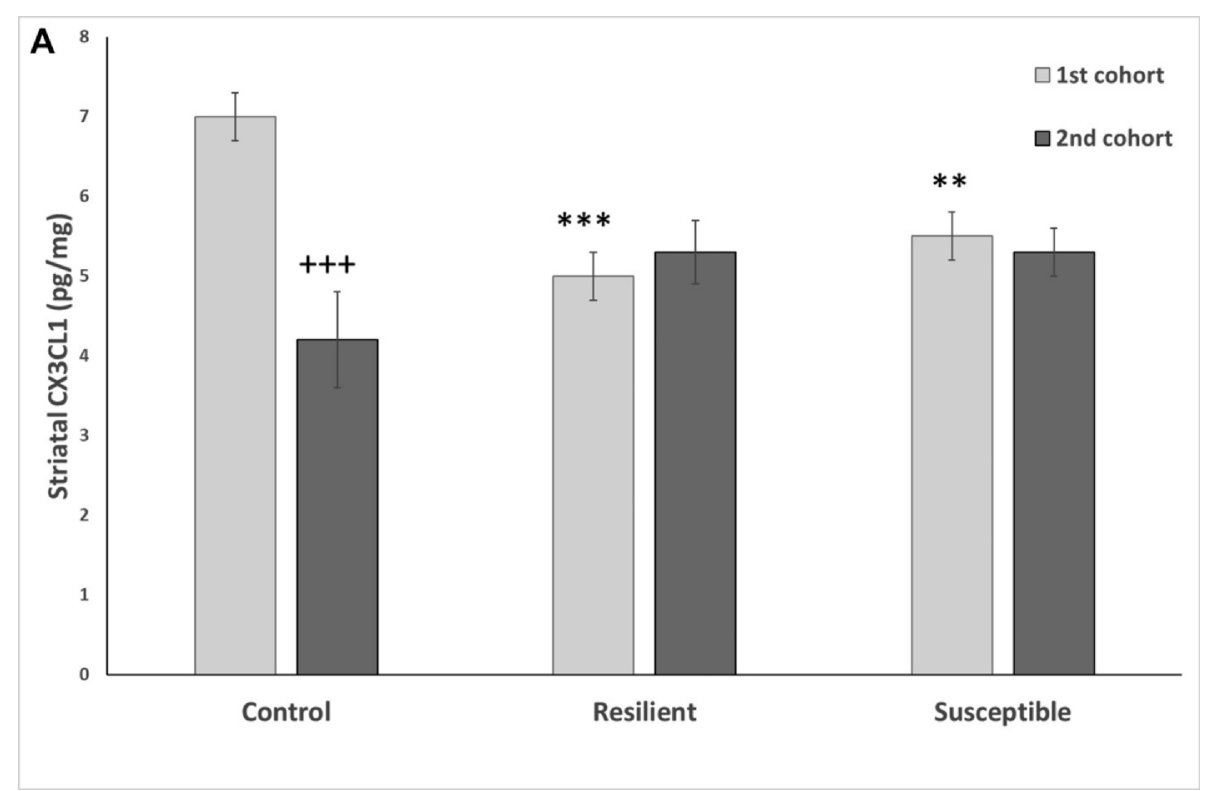

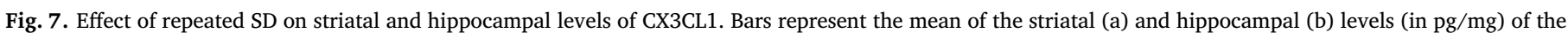

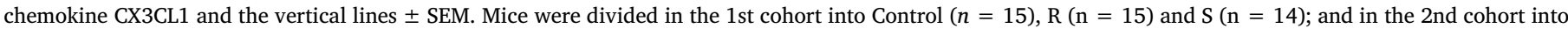

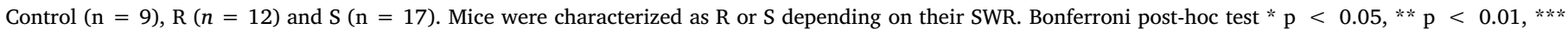

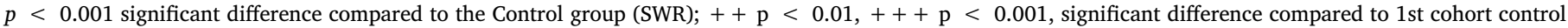
group.

response is present in several behavioral domains. It has to be taken into consideration that in all of these studies only one dose of cocaine was used. It is possible that, with effective doses, differences in the time needed to reach extinction and in the vulnerability to reinstate the preference were also observed between resilient and susceptible animals.

In agreement with our results, Krishnan et al. (2007) also observed an increase in the conditioned rewarding effects of cocaine in susceptible animals (according to their SWR) $24 \mathrm{~h}$ after the last SD. We have extended these results, showing that this susceptibility lasted for at least 3 weeks after the last SD, and it is also observed in cocaine SA. Clinical reports have also confirmed the correlation of depressive symptoms with reward dysfunction responses. Studies in adult or adolescent humans affected by depression showed reward system dysfunction with reduced striatal activation during the execution of rewarding tasks (Drevets et al., 2008; Forbes et al., 2009; Pizzagalli et al., 2009). A resilient phenotype to social stress involves coordinated biological mechanisms in numerous systems, both peripheral and central, and can occur in some domains, such as depression-like behaviors or increased cocaine reward, but not in others, such as anxiety or corticosterone response to stress (Krishnan et al., 2007). The present study also corroborates that the corticosterone response to SD does no differ between resilient and susceptible mice, in agreement with previous reports (Schwendt et al., 2018).

Susceptible mice although also showed higher cocaine intake in the SA procedure than resilient, did not present differences with respect control animals. Equally susceptible mice reached higher ratio and number of active nosepoke in the progressive ratio than control and

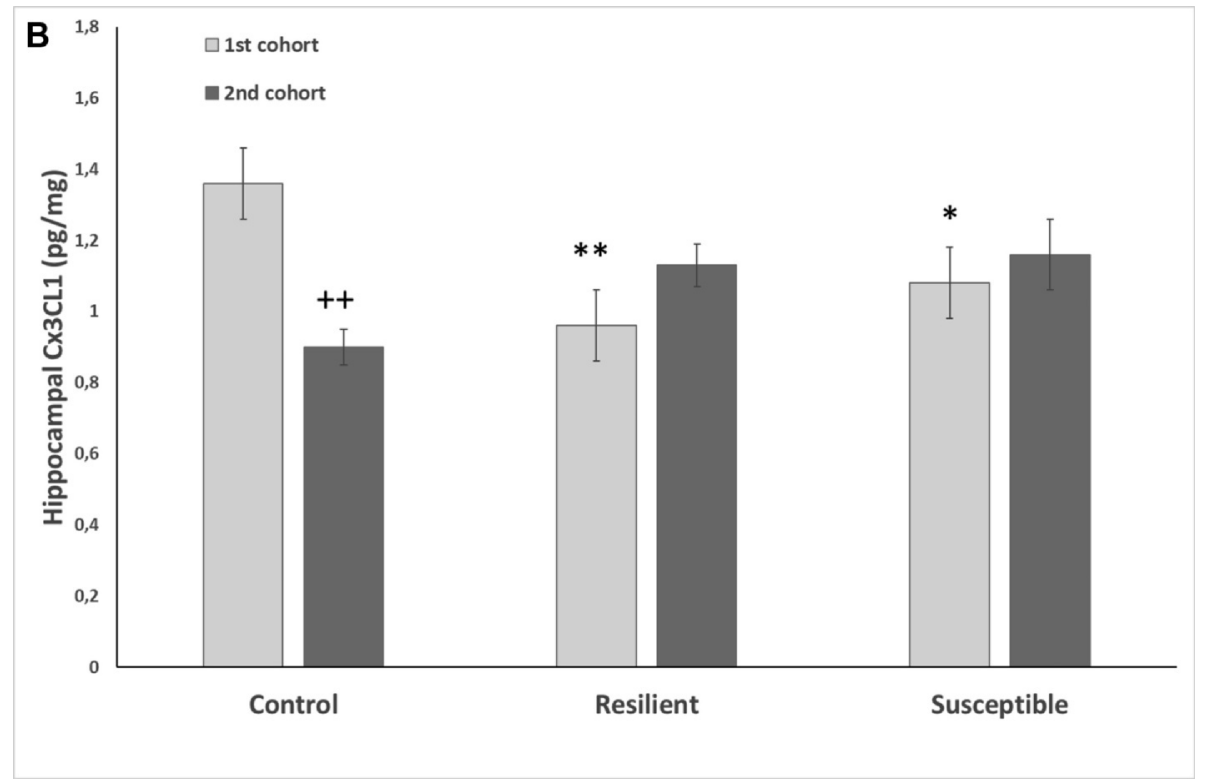

Fig. 7. (continued) 


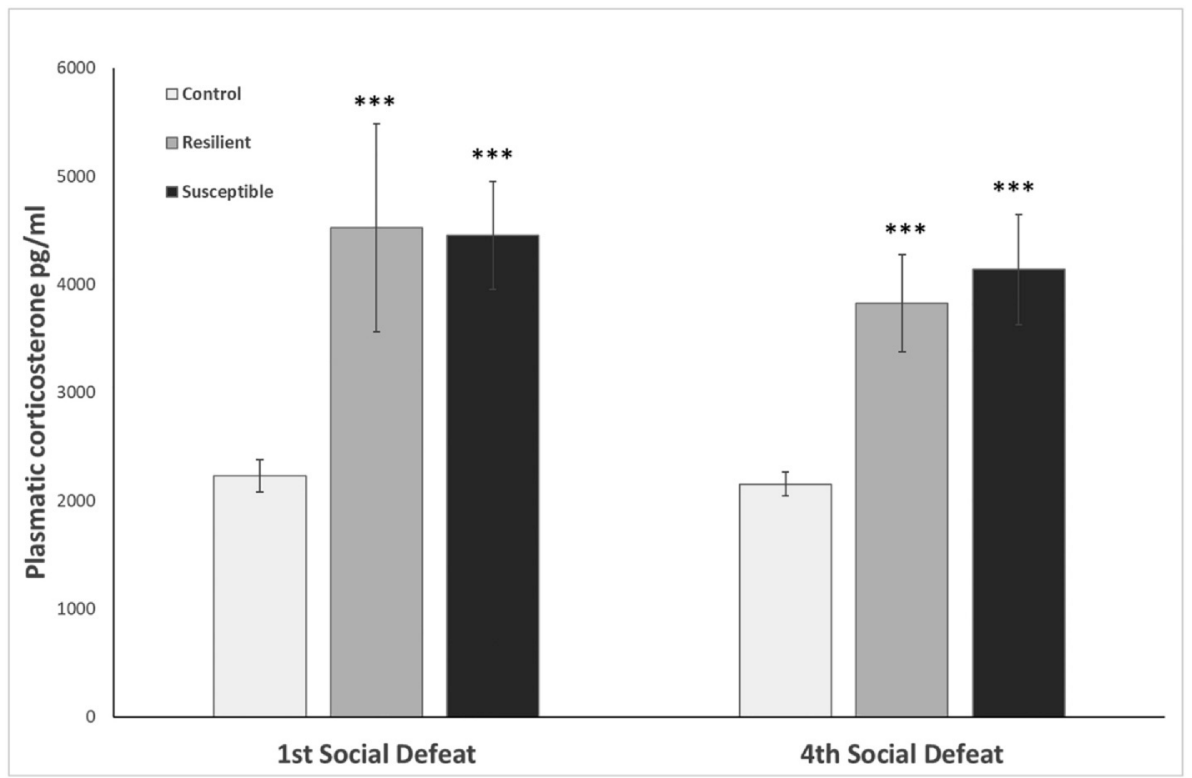

Fig. 8. Social defeat increased plasmatic corticosterone levels in $\mathrm{R}$ and $\mathrm{S}$ mice. Bars represent the mean of the plasmatic corticosterone levels (in pg/ ml) $30 \mathrm{~min}$ after the 1st and 4th social defeat in Control $(n=10), R(n=12)$ and $S(n=15)$ and the vertical lines \pm SEM. Mice were characterized as $\mathrm{R}$ or $S$ depending on their SWR. Bonferroni post-hoc test $* * * \mathrm{p}<0.001$ significant difference compared to their corresponding Control group. resilient animals although without reaching statistical significance. A recent study of Schwendt et al. (2018) did not find differences between resilient and susceptible rats in the number of cocaine self-administration infusions. Similar results were found by Hadad et al. (2016) after 1 daily hour exposure to cocaine self-administration, although an increase in infusions was observed in susceptible rats on the first day of long exposure to cocaine ( $6 \mathrm{~h} /$ day $)$. In these studies, the model of stress is different, based on the predator scent stress model, and the classification of the rats into resilient and susceptible is based on the anxiety profile. However, both analyzed the relationship between resilience to stress effects and cocaine reward. While the CPP evaluates the role of the environmental cues that modulate a drug's rewarding effects, the SA procedure assesses the animals' motivation to obtain the drug (Aguilar et al., 2009). The CPP and SA paradigms evaluate different aspects of reward, and thus, different characteristics of addictive behavior.

Our protocol of social stress, which consists of four social defeat episodes at intervals of $48 \mathrm{~h}$ during which the intruder animals are undisturbed in their home cages, is less intense than the chronic stress models that are usually employed to study resilience to social stress. With our less intense protocol, the OF1 strain of mice showed a profound increase in the rewarding effects of cocaine, measured with the CPP and SA procedures (Montagud-Romero et al., 2016, 2017, 2018; Ferrer-Pérez et al., 2018), as well as a clear increase in inflammatory parameters (Ferrer-Pérez et al., 2019; Rodríguez-Arias et al., 2018; Montagud-Romero et al., 2020). Several reports have suggested that the C57BL/6 strain is less susceptible to stress than other strains (Dadomo et al., 2011; Razzoli et al., 2011a and 2011b). In line with these studies and following our protocol of social stress, C57BL/6 animals did not show the profound effects we have traditionally observed in our former experiments using OF1 mice. Therefore, the model we have employed would appear to be a mild stress applied to a non-susceptible population. This model allows us to unravel subtle mechanisms of resilience that could be overwhelmed by a higher level of stress. At the same time, it enables us to characterize animals that are highly susceptible to social stress.

\subsection{Proactive coping promotes resilience while passive-reactive coping characterizes susceptible animals}

Active coping is one of the psychosocial factors traditionally associated with resilience (Feder et al., 2009). Recent studies have shown that strategies for coping with social stress are associated with resilience to the increased social avoidance or anxiety-like behavior exhibited after social stress procedures (Finnell and Wood, 2016; Krishnan, 2014; Russo et al., 2012). Moreover, mice that are resilient to develop anxiety when exposed to odor of a depredator exhibit changes in their dopaminergic system, suggesting a particular response of these animals to cocaine (Brodnik et al., 2017). In a previous study, we report that mice resilient to stress-induced increases in cocaine reward display less flee and avoidance behaviors during the intruder-resident encounter (Ródenas-González et al., 2020). The results of the present study confirm once again that susceptible mice adopt a passive-reactive coping profile during social defeat encounters, employing more time in flee/avoidance and submissive/defensive behaviors during the social defeat than those categorized as resilient. Differently to resilient, susceptible mice did not increased time in avoidance and flee in the fourth encounter, which indicates lack of behavioral flexibility to the inescapable social defeat experience. Behavioral flexibility in coping strategies that has been associated with emotional resilience, less reactivity of the HPA axis, and increased neuroplasticity (Hawley et al., 2010; Lambert et al., 2014). In this way, our results indicate that active coping and adequate adaptation reduce the enhanced cocaine-seeking behavior induced by exposure to stress.

\subsection{Susceptible mice showed increased levels of IL-6}

Among the many mechanisms involved in SD effects, neuroinflammatory processes are one of the most widely studied (for review see Montagud-Romero et al., 2018). Neuroinflammation is not only activated by harmful stimuli, but also by psychological stress (Xanthos and Sandkühler, 2014); indeed, numerous studies have shown that SD induces neuroinflammation. Cytokine production is initiated through activation of the inflammasome - stimulated by toll-like receptor 4 (TLR4), among other factors - which in turn activates the release of CRF and the initiation of the stress response (Iwata et al., 2013). As a result of the blood brain barrier's increased permeability due to SD, immune cells can easily penetrate the CNS (Rodríguez-Arias et al., 2017). A long-term increase in the number of macrophages, activation of microglia (Rodríguez-Arias et al., 2018; Stankiewicz et al., 2015), increase in pro-inflammatory cytokines such as IL-1 $\beta$ or IL-6 (Ferrer-Pérez et al., 2018; Wohleb et al., 2011, 2012, 2014), and decreases in chemokines such as CX3CL1 (Montagud-Romero et al., 2019) have been described in rodents after exposure to SD stress.

In the present study, we further compared susceptible and resilient 
mice to identify individual differences in the neuroinflammatory mechanisms underlying the social stress-induced increase in cocaine reward. Previous studies based on resilience to depressive-like behavior induced by SD have reported that susceptible mice exhibit increased levels of cytokines such as IL-6, monocyte chemoattractant protein (MCP-1), or IL-1ß (Hodes et al., 2014; Stewart et al., 2015; Wood et al., 2015). In addition, resilient animals exhibit enhanced expression of anti-inflammatory cytokines IL-4 and IL-10 (Hodes et al., 2014; Stewart et al., 2015). Our results showed for the first time that the increase in IL- 6 in susceptible animals is maintained even one month after the last SD experience. Susceptible mice showed an increase of the striatal and hippocampal levels of the pro-inflammatory cytokine IL-6 when measured 4 days after the last defeat and also after the end of the CPP procedure.

We also studied CX3CL1 levels, which can act as pro- or anti-inflammatory chemokine depending on the type of neuroinflammatory event (Sheridan and Murphy, 2013). We have previously reported a decrease in striatal CX3CL1 levels after the 4th SD, which was maintained after cocaine-induced CPP (Montagud-Romero et al., 2019), while no changes were observed in the HPC. In the present work, we observed a decrease in striatal and hippocampal CX3CL1 levels in all defeated mice after the last SD (1st cohort of mice). After the CPP (2nd cohort of mice), probably due to the doses of cocaine administered during the procedure, all mice showed lower striatal and hippocampal CX3CL1 levels in comparison with control animals of the 1st cohort of mice, non-stressed and non-exposed to cocaine. Thus, striatal and hippocampal levels of CX3CL1 were affected by social defeat and also by cocaine administration. For many authors, an increase in endogenous CX3CL1 maintains microglia in a repressed state (Harrison et al., 1998; Ransohoff et al., 2007; Biber et al., 2007; Ransohoff and Perry, 2009). Thus, CX3CL1 signaling mediates a neuroprotective role. In this line, we have previously reported that social defeat induces a decrease of this chemokine and, moreover, that the increase in conditioned cocaine reward was independent of $\mathrm{CX} 3 \mathrm{Cl} 1$ presence (Montagud-Romero et al., 2020). Therefore, these results suggest that CX3CL1 is a sensitive marker for social defeat and cocaine-induced neuroinflammation but it cannot discriminate between susceptible and resilient animals.

To summarize, our results confirm that susceptible animals exhibit depressive-like behavior immediately after social stress and also show a long-term increased response to the rewarding effects of cocaine, as compared to resilient mice. Therefore, SWR predicts further increases in the rewarding effects of cocaine. These susceptible animals present an increased neuroinflammatory response to SD that lasted one month after the end of social stress. Although the complex mechanisms that account for susceptibility or resilience to social stress remain unclear, our results point to multiple adaptive stress responses expressed at different phenotypic levels.

\section{Funding}

This work was supported by the Ministerio de Economía y Competitividad, Dirección General de Investigación, [grant numbers PSI 2017-83023-R]; Spanish Ministry of Economy, Innovation and Competiveness (SAF2016-75347-R) and FPI grant to LAZ BES-2017080066), Spanish Ministry of Health (Plan Nacional sobre Drogas \#2018/007), Instituto de Salud Carlos III, Red de Trastornos Adictivos (RTA) [grant numbers RETICS RD06/0001/1006; RD12/0028/0005; and RD/16/0017/0010] and Unión Europea, Fondos FEDER "A way to build Europe". The Department of Experimental and Health Sciences (UPF) is an "Unidad de Excelencia María de Maeztu" funded by the AEI (CEX2018-000792-M). The authors declare no conflicts of interest.

\section{Ethical statement}

The experimental protocol has been approved by an Institutional Review Committee for the use of animal subjects. Procedures involving mice and their care were conducted according to national, regional and local laws and regulations, which are in compliance with the Directive 2010/63/EU. All the efforts were made to minimize animal suffering and to reduce the number of animals used.

\section{Declaration of Competing Interest}

None.

\section{Acknowledgements}

We wish to thank Brian Normanly and Guillem Chuliá for his English language editing.

\section{References}

Aguilar, M.A., Rodríguez-Arias, M., Miñarro, J., 2009. Neurobiological mechanisms of the reinstatement of drug-conditioned place preference. Brain Res. Rev. 59 (2), 253-277. https://doi.org/10.1016/j.brainresrev.2008.08.002.

Almeida, D.M., 2005. Resilience and vulnerability to daily stressors assessed via diary methods. Curr. Dir. Psychol. Sci. 14 (2), 64-68. https://doi.org/10.1111/j.09637214.2005.00336.x.

Arenas, M.C., Daza-Losada, M., Vidal-Infer, A., Aguilar, M.A., Miñarro, J., RodríguezArias, M., 2014. Capacity of novelty-induced locomotor activity and the hole-board test to predict sensitivity to the conditioned rewarding effects of cocaine. Physiol. Behav. 133, 152-160. https://doi.org/10.1016/j.physbeh.2014.05.028.

Berton, O., McClung, C.A., Dileone, R.J., Krishnan, V., Renthal, W., Russo, S.J., Graham, D., Tsankova, N.M., Bolanos, C.A., Rios, M., Monteggia, L.M., Self, D.W., Nestler, E.J., 2006. Essential role of BDNF in the mesolimbic dopamine pathway in social defeat stress. Science 311 (5762), 864-868 doi:10;311(5762):864-8.

Biber, K., Neumann, H., Inoue, K., Boddeke, H.W., 2007. Neuronal 'On' and 'Off' signals control microglia. Trends Neurosci. 30 (11), 596-602. https://doi.org/10.1016/j. tins.2007.08.007.

Boyson, C.O., Holly, E.N., Shimamoto, A., Albrechet-Souza, L., Weiner, L.A., DeBold, J.F., Miczek, K.A., 2014. Social stress and CRF-dopamine interactions in the VTA: role in long-term escalation of cocaine self-administration. J. Neurosci. 34 (19), 6659-6667. https://doi.org/10.1523/JNEUROSCI.3942-13.2014.

Brockhurst, J., Cheleuitte-Nieves, C., Buckmaster, C.L., Schatzberg, A.F., Lyons, D.M., 2015. Stress inoculation modeled in mice. Transl. Psychiatry 31 (5). https://doi.org/ 10.1038/tp.2015.34. e537.

Brodnik, Z.D., Black, E.M., Clark, M.J., Kornsey, K.N., Snyder, N.W., España, R.A., 2017. Susceptibility to traumatic stress sensitizes the dopaminergic response to cocaine and increases motivation for cocaine. Neuropharmacology 125, 295-307. https://doi. org/10.1016/j.neuropharm.2017.07.032.

Cathomas, F., Murrough, J.W., Nestler, E.J., Han, M.H., Russo, S.J., 2019. Neurobiology of resilience: interface between mind and body. Biol. Psychiatry 86 (6), 410-420. https://doi.org/10.1016/j.biopsych.2019.04.011.

Charney, D.S., 2004. Psychobiological mechanisms of resilience and vulnerability: implications for successful adaptation to extreme stress. Am. J. Psychiatry 161 (2), 195-216. https://doi.org/10.1176/appi.ajp.161.2.195.

Chuang, J.C., Cui, H., Mason, B.L., Mahgoub, M., Bookout, A.L., Yu, H.G., Perello, M., Elmquist, J.K., Repa, J.J., Zigman, J.M., Lutter, M., 2010. Chronic social defeat stress disrupts regulation of lipid synthesis. J. Lipid Res. 51 (6), 1344-1353. https://doi. org/10.1194/jlr.M002196.

Covington 3rd, H.E., Tropea, T.F., Rajadhyaksha, A.M., Kosofsky, B.E., Miczek, K.A., 2008. NMDA receptors in the rat VTA: a critical site for social stress to intensify cocaine taking. Psychopharmacology 197 (2), 203-216. https://doi.org/10.1007/ s00213-007-1024-4.

Covington, H.E., Miczek, K.A., 2001. Repeated social-defeat stress, cocaine or morphine. Psychopharmacology 158 (4), 388-398. https://doi.org/10.1007/s002130100858.

Dadomo, H., Sanghez, V., Di Cristo, L., Lori, A., Ceresini, G., Malinge, I., Parmigiani, S., Palanza, P., Sheardown, M., Bartolomucci, A., 2011. Vulnerability to chronic subordination stress-induced depression-like disorders in adult 129SvEv male mice. Prog. Neuro-Psychopharmacol. Biol. Psychiatry 35 (6), 1461-1471. https://doi.org/ 10.1016/j.pnpbp.2010.11.016.

Dantzer, R., Cohen, S., Russo, S.J., Dinan, T.G., 2018. Resilience and immunity. Brain Behav. Immun. 74, 28-42. https://doi.org/10.1016/j.bbi.2018.08.010.

Drevets, W.C., Price, J.L., Furey, M.L., 2008. Brain structural and functional abnormalities in mood disorders: implications for neurocircuitry models of depression. Brain Struct. Funct. 213 (1-2), 93-118. https://doi.org/10.1007/s00429-008-0189-x.

Dutcher, J.M., Creswell, J.D., 2018. The role of brain reward pathways in stress resilience and health. Neurosci. Biobehav. Rev. 95, 559-567. https://doi.org/10.1016/j. neubiorev. 2018,10.014.

Feder, A., Nestler, E.J., Charney, D.S., 2009. Psychobiology and molecular genetics of resilience. Nat. Rev. Neurosci. 10 (6), 446-457. https://doi.org/10.1038/nrn2649.

Ferrer-Pérez, C., Martinez, T.E., Montagud-Romero, S., Ballestín, R., Reguilón, M.D., Miñarro, J., Rodríguez-Arias, M., 2018. Indomethacin blocks the increased conditioned rewarding effects of cocaine induced by repeated social defeat. PLoS One 13 (12), e0209291. https://doi.org/10.1371/journal.pone.0209291.

Ferrer-Pérez, C., Castro-Zavala, A., Luján, M.A., Filarowska, J., Ballestín, R., Miñarro, J., 
Valverde, O., Rodríguez-Arias, M., 2019. Oxytocin prevents the increase of cocainerelated responses produced by social defeat. Neuropharmacology 146, 50-64. https://doi.org/10.1016/j.neuropharm.2018.11.011.

Finnell, J.E., Wood, S.K., 2016. Neuroinflammation at the interface of depression and cardiovascular disease: evidence from rodent models of social stress. Neurobiol. Stress 4, 1-14. https://doi.org/10.1016/j.ynstr.2016.04.001.

Forbes, E.E., Hariri, A.R., Martin, S.L., Silk, J.S., Moyles, D.L., Fisher, P.M., Brown, S.M., Ryan, N.D., Birmaher, B., Axelson, D.A., Dahl, R.E., 2009. Altered striatal activation predicting real-world positive affect in adolescent major depressive disorder. Am. J. Psychiatry 166 (1), 64-73. https://doi.org/10.1176/appi.ajp.2008.07081336.

Golden, S.A., Covington 3rd, H.E., Berton, O., Russo, S.J., 2011. A standardized protocol for repeated social defeat stress in mice. Nat. Protoc. 6 (8), 1183-1191. https://doi. org/10.1038/nprot.2011.361.

Hadad, N.A., Wu, L., Hiller, H., Krause, E.G., Schwendt, M., Knackstedt, L.A., 2016. Conditioned stress prevents cue-primed cocaine reinstatement only in stress-responsive rats. Stress 19 (4), 406-418. https://doi.org/10.1080/10253890.2016. 1189898.

Han, X., DeBold, J.F., Miczek, K.A., 2017. Prevention and reversal of social stress-escalated cocaine self-administration in mice by intra-VTA CRFR1 antagonism. Psychopharmacology 234 (18), 2813-2821. https://doi.org/10.1007/s00213-0174676-8.

Harrison, J.K., Jiang, Y., Chen, S., Xia, Y., Maciejewski, D., McNamara, R.K., Streit, W.J., Salafranca, M.N., Adhikari, S., Thompson, D.A., Botti, P., Bacon, K.B., Feng, L., 1998. Role for neuronally derived fractalkine in mediating interactions between neurons and CX3CR1-expressing microglia. Proc. Natl. Acad. Sci. U. S. A. 95 (18), 10896-10901. https://doi.org/10.1073/pnas.95.18.10896.

Hawley, D.F., Bardi, M., Everette, A.M., Higgins, T.J., Tu, K.M., Kinsley, C.H., Lambert, K.G., 2010. Neurobiological constituents of active, passive, and variable coping strategies in rats: integration of regional brain neuropeptide $\mathrm{Y}$ levels and cardiovascular responses. Stress 13 (2), 172-183. https://doi.org/10.3109/ 10253890903144621.

Heffner, T.G., Hartman, J.A., Seiden, L.S., 1980. A rapid method for the regional dissection of the rat brain. Pharmacol. Biochem. Behav. 13 (3), 453-456. https://doi. org/10.1016/0091-3057(80)90254-3.

Hodes, G.E., Pfau, M.L., Leboeuf, M., Golden, S.A., Christoffel, D.J., Bregman, D., Rebusi, N., Heshmati, M., Aleyasin, H., Warren, B.L., Lebonté, B., Horn, S., Lapidus, K.A., Stelzhammer, V., Wong, E.H., Bahn, S., Krishnan, V., Bolaños-Guzman, C.A., Murrough, J.W., Merad, M., Russo, S.J., 2014. Individual differences in the peripheral immune system promote resilience versus susceptibility to social stress. Proc. Natl. Acad. Sci. 111 (45), 16136-16141. https://doi.org/10.1073/pnas.1415191111.

Iwata, M., Ota, K.T., Duman, R.S., 2013. The inflammasome: pathways linking psychological stress, depression, and systemic illnesses. Brain Behav. Immun. 31, 105-114. https://doi.org/10.1016/j.bbi.2012.12.008.

Koob, G.F., 2008. A role for brain stress systems in addiction. Neuron 59 (1), 11-34 https://doi.org/10.1016/j.neuron.2008.06.012.

Koob, G.F., Schulkin, J., 2019. Addiction and stress: an allostatic view. Neurosci. Biobehav. Rev. 106, 245-262. https://doi.org/10.1016/j.neubiorev.2018.09.008.

Koolhaas, J.M., de Boer, S.F., Buwalda, B., van Reenen, K., 2007. Individual variation in coping with stress: a multidimensional approach of ultimate and proximate mechanisms. Brain Behav. Evol. 70 (4), 218-226. https://doi.org/10.1159/000105485.

Krishnan, V., 2014. Defeating the fear: new insights into the neurobiology of stress susceptibility. Exp. Neurol. 261, 412-416. https://doi.org/10.1016/j.expneurol.2014. 05.012.

Krishnan, V., Han, M.H., Graham, D.L., Berton, O., Renthal, W., Russo, S.J., Laplant, Q., Graham, A., Lutter, M., Lagace, D.C., Ghose, S., Reister, R., Tannous, P., Green, T.A., Neve, R.L., Chakravarty, S., Kumar, A., Eisch, A.J., Self, D.W., Lee, F.S., Tamminga, C.A., Cooper, D.C., Gershenfeld, H.K., Nestler, E.J., 2007. Molecular adaptations underlying susceptibility and resistance to social defeat in brain reward regions. Cell. 131 (2), 391-404. https://doi.org/10.1016/j.cell.2007.09.018.

Kudryavtseva, N.N., Bakshtanovskaya, I.V., Koryakina, L.A., 1991. Social model of depression in mice of C57BL/6J strain. Pharmacol. Biochem. Behav. 38, 315-320. https://doi.org/10.1016/0091-3057(91)90284-9.

Lambert, K.G., Hyer, M.M., Rzucidlo, A.A., Bergeron, T., Landis, T., Bardi, M., 2014. Contingency-based emotional resilience: effort-based reward training and flexible coping lead to adaptive responses to uncertainty in male rats. Front. Behav. Neurosci. 8, 124. https://doi.org/10.3389/fnbeh.2014.00124.

Lynch, W.J., Nicholson, K.L., Dance, M.E., Morgan, R.W., Foley, P.L., 2010. Animal models of substance abuse and addiction: implications for science, animal welfare, and society. Comp. Med. 60 (3), 177-188.

Manzanedo, C., Aguilar, M.A., Rodrí́guez-Arias, M., Miñarro, J., 2001. Effects of dopamine antagonists with different receptor blockade profiles on morphine-induced place preference in male mice. Behav. Brain Res. 121 (1-2), 189-197. https://doi. org/10.1016/S0166-4328(01)00164-4.

Miczek, K.A., Thompson, M.L., Shuster, L., 1982. Opioid-like analgesia in defeated mice. Science 215 (4539), 1520-1522. https://doi.org/10.1126/science.7199758.

Miczek, K.A., Yap, J.J., Covington, H.E., 2008. Social stress, therapeutics and drug abuse: preclinical models of escalated and depressed intake. Pharmacol. Ther. 120 (2), 102-128. https://doi.org/10.1016/j.pharmthera.2008.07.006.

Montagud-Romero, S., Aguilar, M.A., Maldonado, C., Manzanedo, C., Miñarro, J., Rodríguez-Arias, M., 2015. Acute social defeat stress increases the conditioned rewarding effects of cocaine in adult but not in adolescent mice. Pharmacol. Biochem. Behav. 135, 1-12. https://doi.org/10.1016/j.pbb.2015.05.008.

Montagud-Romero, S., Reguilon, M.D., Roger-Sanchez, C., Pascual, M., Aguilar, M.A., Guerri, C., Miñarro, J., Rodríguez-Arias, M., 2016. Role of dopamine neurotransmission in the long-term effects of repeated social defeat on the conditioned rewarding effects of cocaine. Prog. Neuro-Psychopharmacol. Biol. Psychiatry 71,
144-154. https://doi.org/10.1016/j.pnpbp.2016.07.008.

Montagud-Romero, S., Nuñez, C., Blanco-Gandia, M.C., Martínez-Laorden, E., Aguilar, M.A., Navarro-Zaragoza, J., Almela, P., Milanés, M.V., Laorden, M.L., Miñarro, J., Rodríguez-Arias, M., 2017. Repeated social defeat and the rewarding effects of cocaine in adult and adolescent mice: dopamine transcription factors, proBDNF signaling pathways, and the TrkB receptor in the mesolimbic system.

Psychopharmacology 234 (13), 2063-2075. https://doi.org/10.1007/s00213-017. 4612-y.

Montagud-Romero, S., BlancoGandía, M.C., Reguilón, M.D., FerrerPérez, C., Ballestín, R., Miñarro, J., Rodríguez-Arias, M., 2018. Social defeat stress: mechanisms underlying the increase in rewarding effects of drugs of abuse. Eur. J. Neurosci. 48 (9), 2948-2970. https://doi.org/10.1111/ejn.14127.

Montagud-Romero, S., Cantacorps, L., Valverde, O., 2019. Histone deacetylases inhibitor trichostatin a reverses anxiety-like symptoms and memory impairments induced by maternal binge alcohol drinking in mice. J. Psychopharmacol. 33 (12), 1573-1587. https://doi.org/10.1177/0269881119857208.

Montagud-Romero, S., Montesinos, J., Pavón, F.J., Blanco-Gandia, M.C., Ballestín, R., Rodríguez de Fonseca, F., Miñarro, J., Guerri, C., Rodríguez-Arias, M., 2020. Social defeat-induced increase in the conditioned rewarding effects of cocaine: role of CX3CL1. Prog. Neuro-Psychopharmacol. Biol. Psychiatry 96, 109753. https://doi. org/10.1016/j.pnpbp.2019.109753.

Murrough, J.W., Russo, S.J., 2019. The neurobiology of resilience: complexity and Hope. Biol. Psychiatry 86 (6), 406-409. https://doi.org/10.1016/j.biopsych.2019.07.016.

Neisewander, J.L., Peartree, N.A., Pentkowski, N.S., 2012. Emotional valence and context of social influences on drug abuse-related behavior in animal models of social stress and prosocial interaction. Psychopharmacology 224 (1), 33-56. https://doi.org/10. 1007/s00213-012-2853-3.

Ouakinin, S.R.S., Barreira, D.P., Gois, C.J., 2018. Depression and obesity: integrating the role of stress, neuroendocrine dysfunction and inflammatory pathways. Front. Endocrinol. 9, 431. https://doi.org/10.3389/fendo.2018.00431.

Pfau, M.L., Russo, S.J., 2015. Peripheral and central mechanisms of stress resilience. Neurobiol. Stress. 1, 66-79. https://doi.org/10.1016/j.ynstr.2014.09.004.

Pizzagalli, D.A., Holmes, A.J., Dillon, D.G., Goetz, E.L., Birk, J.L., Bogdan, R., Dougherty, D.D., Iosifescu, D.V., Rauch, S.L., Fava, M., 2009. Reduced caudate and nucleus accumbens response to rewards in unmedicated individuals with major depressive disorder. Am. J. Psychiatry 166 (6), 702-710. https://doi.org/10.1176/appi.ajp. 2008.08081201.

Quadros, I.M., Miczek, K.A., 2009. Two modes of intense cocaine bingeing: increased persistence after social defeat stress and increased rate of intake due to extended access conditions in rats. Psychopharmacology 206 (1), 109-120. https://doi.org/10. 1007/s00213-009-1584-6.

Ransohoff, R.M., Perry, V.H., 2009. Microglial physiology: unique stimuli, specialized responses. Annu. Rev. Immunol. 27, 119-145. https://doi.org/10.1146/annurev. immunol.021908.132528.

Ransohoff, R.M., Liu, L., Cardona, A.E., 2007. Chemokines and chemokine receptors: multipurpose players in neuroinflammation. Int. Rev. Neurobiol. 82, 187-204. https://doi.org/10.1016/S0074-7742(07)82010-1.

Razzoli, M., Carboni, L., Andreoli, M., Ballottari, A., Arban, R., 2011a. Different susceptibility to social defeat stress of BalbC and C57BL6/J mice. Behav. Brain Res. 216 (1), 100-108. https://doi.org/10.1016/j.bbr.2010.07.014.

Razzoli, M., Carboni, L., Andreoli, M., Michielin, F., Ballottari, A., Arban, R., 2011b. Strain-specific outcomes of repeated social defeat and chronic fluoxetine treatment in the mouse. Pharmacol. Biochem. Behav. 97 (3), 566-576. https://doi.org/10.1016/j. pbb.2010.09.010.

Reguilón, M.D., Montagud-Romero, S., Ferrer-Pérez, C., Roger-Sánchez, C., Aguilar, M.A., Miñarro, J., Rodríguez-Arias, M., 2017. Dopamine D2 receptors mediate the increase in reinstatement of the conditioned rewarding effects of cocaine induced by acute social defeat. Eur. J. Pharmacol. 799, 48-57. https://doi.org/10.1016/j.ejphar.2017. 01.039 .

Ródenas-González, F., Blanco-Gandía, M.C., Miñarro López, J., Rodriguez-Arias, M., 2020. Behavioral and neuroimmune characterization of resilience to social stress: rewarding effects of cocaine. Adicciones 0 (0), 1348. https://doi.org/10.20882/ adicciones.1348.

Rodríguez-Arias, M., Minarro, J., Aguilar, M.A., Pinazo, J., Simon, V.M., 1998. Effects of risperidone and SCH 23390 on isolation-induced aggression in male mice. Eur. Neuropsychopharmacol. 8 (2), 95-103. https://doi.org/10.1016/S0924-977X(97).

Rodríguez-Arias, M., Valverde, O., Daza-Losada, M., Blanco-Gandía, M.C., Aguilar, M.A., Miñarro, J., 2013a. Assessment of the abuse potential of MDMA in the conditioned place preference paradigm: role of CB1 receptors. Prog. Neuro-Psychopharmacol. Biol. Psychiatry 47, 77-84. https://doi.org/10.1016/j.pnpbp.2013.07.013.

Rodríguez-Arias, M., Navarrete, F., Blanco-Gandia, M.C., Arenas, M.C., Bartoll-Andrés, A., Aguilar, M.A., Rubio, G., Miñarro, J., Manzanares, J., 2016. Social defeat in adolescent mice increases vulnerability to alcohol consumption. Addict. Biol. 21 (1), 87-97. https://doi.org/10.1111/adb.12184.

Rodríguez-Arias, M., Montagud-Romero, S., Rubio-Araiz, A., Aguilar, M.A., MartínGarcía, E., Cabrera, R., Maldonado, R., Porcu, F., Colado, M.I., Miñarro, J., 2017. Effects of repeated social defeat on adolescent mice on cocaine-induced CPP and selfadministration in adulthood: integrity of the blood-brain barrier. Addict. Biol. 22 (1), 129-141. https://doi.org/10.1111/adb.12301.

Rodríguez-Arias, M., Montagud-Romero, S., Carrion, A.M.G., Ferrer-Pérez, C., PérezVillalba, A., Marco, E., López Gallardo, M., Viveros, M.P., Miñarro, J., 2018. Social stress during adolescence activates long-term microglia inflammation insult in reward processing nuclei. PLoS One 13 (10), e0206421. https://doi.org/10.1371 journal.pone.0206421.

Ruisoto, P., Contador, I., 2019. The role of stress in drug addiction. An integr. Rev. Physiol. Behav. 202, 62-68. https://doi.org/10.1016/j.physbeh.2019.01.022. 
Russo, S.J., Murrough, J.W., Han, M.H., Charney, D.S., Nestler, E.J., 2012. Neurobiology of resilience. Nat. Neurosci. 15 (11), 1475-1484. https://doi.org/10.1038/nn.3234.

Rygula, R., Abumaria, N., Flügge, G., Fuchs, E., Rüther, E., Havemann-Reinecke, U., 2005. Anhedonia and motivational deficits in rats: impact of chronic social stress. Behav. Brain Res. 162 (1), 127-134. https://doi.org/10.1016/j.bbr.2005.03.009.

Schwendt, M., Shallcross, J., Hadad, N.A., Namba, M.D., Hiller, H., Wu, L., Krause, E.G., Knackstedt, L.A., 2018. A novel rat model of comorbid PTSD and addiction reveals intersections between stress susceptibility and enhanced cocaine seeking with a role for mGlu5 receptors. Transl. Psychiatry 8 (1), 209. https://doi.org/10.1038/s41398018-0265-9.

Sheridan, G.K., Murphy, K.J., 2013. Neuron-glia crosstalk in health and disease: fractalkine and CX3CR1 take centre stage. Open Biol. 183 (12), 130181. https://doi.org/ 10.1098/rsob.130181.

Shimamoto, A., 2018. Social defeat stress, sex, and addiction-like behaviors. Int. Rev. Neurobiol. 140, 271-313. https://doi.org/10.1016/bs.irn.2018.07.009.

Soria, G., Barbano, M.F., Maldonado, R., Valverde, O., 2008. A reliable method to study cue-, priming-, and stress-induced reinstatement of cocaine self-administration in mice. Psychopharmacology 199 (4), 593-603. https://doi.org/10.1007/s00213-0081184-x.

Stankiewicz, A.M., Goscik, J., Majewska, A., Swiergiel, A.H., Juszczak, G.R., 2015. The effect of acute and chronic social stress on the hippocampal transcriptome in mice. PLoS One 10 (11), e0142195. https://doi.org/10.1371/journal.pone.0142195.

Stewart, A.M., Roy, S., Wong, K., Gaikwad, S., Chung, K.M., Kalueff, A.V., 2015. Cytokine and endocrine parameters in mouse chronic social defeat: implications for translational 'cross-domain' modeling of stress-related brain disorders. Behav. Brain Res. 276, 84-91. https://doi.org/10.1016/j.bbr.2014.08.037.

Tornatzky, W., Miczek, K.A., 1993. Long-term impairment of autonomic circadian rhythms after brief intermittent social stress. Physiol. Behav. 53 (5), 983-993. https://doi.org/10.1016/0031-9384(93)90278-N.

Vidal-Infer, A., Arenas, M.C., Daza-Losada, M., Aguilar, M.A., Miñarro, J., RodríguezArias, M., 2012. High novelty-seeking predicts greater sensitivity to the conditioned rewarding effects of cocaine. Pharmacol. Biochem. Behav. 102 (1), 124-132. https:// doi.org/10.1016/j.pbb.2012.03.031.
Wohleb, E.S., Hanke, M.L., Corona, A.W., Powell, N.D., Stiner, L.M., M.S, Bailey, M.T., Nelson, R.J., Godbout, J.P., Sheridan, J.F., 2011. $\beta$-Adrenergic receptor antagonism prevents anxiety-like behavior and microglial reactivity induced by repeated social defeat. J. Neurosci. 31 (17), 6277-6288. https://doi.org/10.1523/JNEUROSCI.045011.2011.

Wohleb, E.S., Fenn, A.M., Pacenta, A.M., Powell, N.D., Sheridan, J.F., Godbout, J.P. 2012. Peripheral innate immune challenge exaggerated microglia activation, increased the number of inflammatory CNS macrophages, and prolonged social withdrawal in socially defeated mice. Psychoneuroendocrinology 37 (9), 1491-1505. https://doi.org/10.1016/j.psyneuen.2012.02.003.

Wohleb, E.S., Patterson, J.M., Sharma, V., Quan, N., Godbout, J.P., Sheridan, J.F., 2014 Knockdown of interleukin-1 receptor type-1 on endothelial cells attenuated stressinduced neuroinflammation and prevented anxiety-like behavior. J. Neurosci. 34 (7), 2583-2591. https://doi.org/10.1523/JNEUROSCI.3723-13.2014.

Wood, S.K., Bhatnagar, S., 2015. Resilience to the effects of social stress: evidence from clinical and preclinical studies on the role of coping strategies. Neurobiol. Stress 1, 164-173. https://doi.org/10.1016/j.ynstr.2014.11.002.

Wood, S.K., Walker, H.E., Valentino, R.J., Bhatnagar, S., 2010. Individual differences in reactivity to social stress predict susceptibility and resilience to a depressive phenotype: role of corticotropin-releasing factor. Endocrinology 151 (4), 1795-1805. https://doi.org/10.1210/en.2009-1026.

Wood, S.K., Wood, C.S., Lombard, C.M., Lee, C.S., Zhang, X.Y., Finnell, J.E., Valentino, R.J., 2015. Inflammatory factors mediate vulnerability to a social stress-induced depressive-like phenotype in passive coping rats. Biol. Psychiatry 78 (1), 38-48. https://doi.org/10.1016/j.biopsych.2014.10.026.

Xanthos, D.N., Sandkühler, J., 2014. Neurogenic neuroinflammation: inflammatory CNS reactions in response to neuronal activity. Nat. Rev. Neurosci. 15 (1), 43-53. https:// doi.org/10.1038/nrn3617.

Yap, J.J., Chartoff, E.H., Holly, E.N., Potter, D.N., Carlezon Jr., W.A., Miczek, K.A., 2015. Social defeat stress-induced sensitization and escalated cocaine self-administration: the role of ERK signaling in the rat ventral tegmental area. Psychopharmacology 232 (9), 1555-1569. https://doi.org/10.1007/s00213-014-3796-7. 